\title{
Dynamics of the Bacillus subtilis Min system
}

2

3 Helge Feddersen ${ }^{1,3}$, Laeschkir Würthner ${ }^{2}$, Erwin Frey ${ }^{2}$ and Marc Bramkamp ${ }^{1,3}$ *

$4{ }^{1}$ Institute for General Microbiology, Christian-Albrechts-University Kiel, Am Botanischen Garten 1-9,

524118 Kiel, Germany

$6 \quad{ }^{2}$ Arnold-Sommerfeld-Center for Theoretical Physics and Center for NanoScience, Ludwig-Maximilians-

7 Universität München, Theresienstr. 37, 80333 Munich, Germany

$8{ }^{3}$ Ludwig-Maximilians-Universität München, Faculty of Biology, Großhaderner Straße 2-4, 82152

$9 \quad$ Planegg-Martinsried, Germany

10

Running title: Min system dynamics in Bacillus

*To whom correspondence should be addressed: Marc Bramkamp, Christian-Albrechts-University Kiel, Institute for General Microbiology, Am Botanischen Garten 1-9, 24118 Kiel, Germany, Email: 
22

\section{Summary}

Division site selection is a vital process to ensure generation of viable offspring. In many rod-shaped bacteria a dynamic protein system, termed the Min system, acts as a central regulator of division site placement. The Min system is best studied in Escherichia coli where it shows a remarkable oscillation from pole to pole with a time-averaged density minimum at midcell. Several components of the Min system are conserved in the Gram-positive model organism Bacillus subtilis. However, in B. subtilis it is believed that the system forms a stationary bipolar gradient from the cell poles to midcell. Here, we show that the Min system of $B$. subtilis localizes dynamically to active sites of division, often organized in clusters. We provide physical modelling using measured diffusion constants that describe the observed enrichment of the Min system at the septum. Modelling suggests that the observed localization pattern of Min proteins corresponds to a dynamic equilibrium state. Our data provide evidence for the importance of ongoing septation for the Min dynamics, consistent with a major role of the Min system to control active division sites, but not cell pole areas.

\section{Keywords}
B. subtilis, Min system, cell division, FRAP; PALM, super resolution microscopy, protein patterns, reaction diffusion equations,

\section{Introduction}

The spatiotemporal regulation of cell division in bacteria is an essential mechanism ensuring correct partitioning of DNA to produce viable daughter cells upon division. The best studied model organisms in this aspect are the rod-shaped Gram-positive and Gram-negative bacteria Bacillus subtilis and Escherichia coli, respectively. Both species divide precisely at the geometric middle via binary fission. The earliest observed event in this process is the formation of the Z-ring, a ring-like structure consisting of polymerized FtsZ proteins, a highly conserved homologue of eukaryotic tubulin [1-5]. Once assembled, FtsZ acts as a dynamic scaffold and recruits a diverse set of proteins forming the divisome, a complex that mediates cytokinesis [6-8]. Recently, treadmilling of FtsZ filaments was 
shown to drive circumferential peptidoglycan (PG) synthesis [9]. However, it is still not fully understood how FtsZ finds the precise midplane of the cell. In E. coli and B. subtilis the nucleoid occlusion (NO) and the Min system, two negative FtsZ regulators, have been shown to confine its action spatially to the center of the cell. Noc in B. subtilis and SImA in E. coli bind to DNA and inhibit FtsZ polymerization across the nucleoid [10-14]

The Min system in E. coli consists of the three proteins MinC, MinD and MinE [15, 16], and has been studied extensively both experimentally [17-29] and theoretically [29-35]. MinC is the inhibitor of Zring formation, inhibiting the bundling of FtsZ filaments [22, 36-39]. MinC is localized through MinD, a protein that belongs to the WACA (Walker A cytomotive ATPase) family [40, 41]. Upon binding ATP, Min D dimerizes and associates with the membrane through a conserved C-terminal membrane targeting sequence (MTS) $[3,42,43]$. MinC and MinD were described to form large ATP-dependent alternating polymers that assemble cooperatively and locally inhibit FtsZ bundling [44, 45]. In absence of MinCD, cells frequently produce the name giving anucleate minicells $[46,47]$. The $E$. coli MinCD complexes are disassembled and detached from the membrane by MinE, a protein that forms a ring-like density profile at the rim of MinD assemblies $[48,49]$ and binds to the membrane via an amphipathic helix serving as membrane targeting sequence (MTS) [50, 51]. MinE triggers ATPase activity of MinD, leading to membrane detachment of MinCD [27]. Cytosolic MinD rebinds ATP and binds the membrane again, thereby leading to a remarkably robust oscillation of the Min system in $E$. coli $[25,27,52,53]$. Min protein dynamics are a paradigmatic example of cellular self-organization [54]. Due to the simplicity of the system, it has been subject to several molecular modelling studies and in vitro reconstructions [26-35].

The Min system in B. subtilis lacks MinE as essential factor that is responsible for Min oscillation in $E$. coli. In contrast, Min proteins do not oscillate in B. subtilis but are believed to form a stationary bipolar gradient decreasing towards midcell, therefore restricting assembly of a functional FtsZ ring to the midplane of the cell $[3,8]$. The spatial cue for a gradient in B. subtilis is provided by DivIVA [55, 56]. DivIVA targets and localizes to negatively curved membrane regions [57]. MinJ acts as a 
molecular bridge between MinD and DivIVA $[58,59]$. MinJ contains six predicted transmembrane helices and a PDZ domain, which often participate in protein-protein interactions [60]. Due to the polar targeting of DivIVA, MinCDJ should form a stationary polar gradient decreasing towards midcell, restricting FtsZ polymerization spatially at midcell. However, several studies suggest that the B. subtilis Min system may rather act downstream of FtsZ ring formation by preventing re-initiation of division at former sites of cytokinesis $[58,59,61]$.

We have recently analyzed DivlVA dynamics in B. subtilis and found that Min proteins redistribute from the cell poles to midcell as soon as a septum is formed [62], which prompted us to reanalyze Min protein dynamics in this organism. To this end, we generated a set of new fusions to DivlVA, MinD and MinJ. To avoid overexpression artifacts that would corrupt protein dynamics studies, we generated strains where the native gene copies were replaced by functional fluorescent fusions. These allelic replacements were used to determine precise molecule counts per cell. Using fluorescent recovery after photo-bleaching (FRAP) we determined protein dynamics of the individual Min proteins. We then calculated protein diffusion coefficients that were further used for modeling and simulations of the observed Min dynamics. We finally analyzed the nanoscale spatial distribution of the Min proteins in B. subtilis by single molecule localization microscopy (SMLM). Our data are consistent with a dynamic turnover of MinD between membrane and cytosol. Moreover, our SMLM data support a model in which the Min complex is in a dynamic steady state that is able to relocalize from the cell pole to the septum facilitated by a geometric cue, namely the invagination of the membrane at the septum. Based on our experimental data, we propose a minimal theoretical model for the Min dynamics in B. subtilis in realistic 3D cell geometry. The model is based on a reactiondiffusion system for MinD and incorporates the effects of DivlVA and MinJ implicitly through spacedependent recruitment and detachment processes. Our computational analysis of the mathematical model reproduces qualitative features of the Min dynamics in B. subtilis and shows that localization of MinD to the poles or septum corresponds to a dynamic equilibrium state. Furthermore, our model suggests that a geometric effect alone could explain septum localization of MinD once DivlVA is 
99

100

101

102

\section{3}

104

105

106

107

108

109

110

111

112

113

114

115

recruited to the growing septum, therefore highlighting the importance of geometry effects that cannot be captured in a simplified one-dimensional (1D) model.

\section{Results:}

\section{Construction of fluorescent fusions with native expression level}

Even though the Min system in B. subtilis has been extensively investigated before, most studies were conducted using strains that overexpress fluorescent fusions from ectopic locations upon artificial induction $[63,64]$, leading to non-native expression levels that can alter the native behavior of fine-tuned systems like the Min system. Additionally, even small populations of a protein from overexpression make it difficult to identify a dynamic fraction through diffraction limited microscopy [65]. Hence, we aimed to re-characterize the dynamics of the Min components in B. subtilis using strains that avoid or minimize overexpression artifacts and, hence, created a set of allelic replacements (Fig. S1, Fig. S2).

Dysfunctionality or deletion of Min components in B. subtilis manifests in an easily observable phenotype of increased cell length and DNA free minicells (Tab. 1). This allows rapid evaluation of the functionality of fluorescent-fusions in the constructed strains by comparing cell length and number of minicells between mutant and the wild-type strain (Tab. 1).

Here, we generated functional fusions to MinD (Dendra2 [66]) and MinJ (msfGFP [67] and mNeonGreen [68]) as judged by cell length, number of minicells and subcellular protein localization (Fig. S2, Tab. 1). Dendra2-MinD displayed a phenotype comparable to the wild-type, but could unfortunately not be used for FRAP studies due to the fluorophore characteristics. Therefore, another strain expressing msfGFP fused to MinD was created. This fusion protein was largely functional according to cell length and number of minicells (Fig. S2, Tab. 1). When msfGFP-minD was transformed in a genetic background of $\triangle \min J$ or $\triangle \operatorname{div} I V A$, the fluorescent signal was, as expected, 
distributed in the cytosol, sometimes forming small foci. MinJ-msfGFP also lost its polar and septal localization upon deletion of $\operatorname{divIVA}$, as it has been reported before [58]. Hence, these strains were not used for further analysis of protein dynamics.

When constructing DivIVA fluorescent fusions, several different fluorophores (FPs) were successfully fused to DivIVA, namely mCherry2, mNeonGreen, Dendra2, PAmCherry, mGeosM and Dronpa [66, 68-72], with linkers between 2 and 15 amino acids. Unfortunately, all of them showed a mild or strong phenotype, some even severe protein mislocalization, hinting towards limited functionality of these DivIVA fusion proteins ([73] and data not shown). Since this did not meet the set standards for this study, we turned towards strain 1803 [74], carrying a divIVA-GFP copy with its native promoter in the ectopic amyE locus. While DivIVA-GFP has been shown to not fully complement a $\triangle$ divIVA strain [74, 75], it still localizes correctly and can be used for studies of DivlVA dynamics [62, 75]. Additionally, we performed FRAP on DivIVA-mNeonGreen, which only shows a mild phenotype (Tab. 1), in wild type and Min knockout backgrounds to be able to compare it with the effect of the extra copy of DivlVA in strain 1803 (Fig. S3).

All fluorescent fusions were analyzed via SDS-PAGE with subsequent visualization through in-gel fluorescence or western blotting (Fig. S4. We used in-gel fluorescence to obtain estimations about the number of molecules of the Min proteins during mid-exponential phase. We calculated protein numbers relative to the total amount of MinD that was quantified under same growth conditions using mass spectrometry before [76] (Tab. S1, Fig. S5). MinD proteins are highly abundant (3544 proteins per cell), while DivIVA numbers are less than $50 \%$ of that (1690 proteins per cell). MinJ has only $16 \%$ of MinD abundancy (576 proteins per cell).

\section{The Min system in B. subtilis is in a dynamic steady state}

Strains expressing functional Min fusions were then used for microscopic analysis of protein dynamics using fluorescent recovery after photobleaching (FRAP) experiments. Surprisingly, all three 
components of the Min system showed relatively fast diffusion in FRAP (Error! Reference source not

found., Figure 2, Tab. 2). Unfortunately, Dendra2-MinD could not be used for FRAP studies, because excitation with $488 \mathrm{~nm}$ leads to a significant green to red conversion during the course of the experiment. When converting all proteins from green to red prior the FRAP experiment with UV light (405 $\mathrm{nm}$ ), the red fluorescent signal was poor and bleaching of most proteins occurred during the first image acquisitions, prohibiting reliable quantification. Upon converting protein locally at one of the poles or a septum with a short laser pulse at $405 \mathrm{~nm}$ and subsequent imaging in the red channel, very fast diffusion of converted Dendra2-MinD throughout the cell could be observed (data not shown). However, the signal was too dim to be quantified satisfactorily. Therefore, we utilized the strain expressing msfGFP-MinD (BHF017) and observed a fast fluorescence recovery $\left(T_{1 / 2}=7.55 \mathrm{~s}\right)$, indicating rapid exchange of MinD molecules around the division septum, similar to what was previously reported for MinC [65]. Bleaching of $\operatorname{MinD}$ at a septum was very efficient (Error!

Reference source not found. a, upper panel), the exchange of MinD molecules at the bleached spot appeared to include proteins localized distant from the bleached septum as well as in the vicinity, since the fluorescent signal in the cell reduced evenly over the whole cell length during recovery. Furthermore, around $79 \%$ of the msfGFP-MinD population appeared to be mobile (Figure 2, Tab. 2).

Next, we investigated MinJ-msfGFP fluorescence recovery, which was considerably slower compared to msfGFP-MinD, but still indicating protein diffusion $\left(\mathrm{T}_{1 / 2}=62.35 \mathrm{~s}\right)$. MinJ contains six predicted transmembrane helices and therefore, a slower recovery was expected. Again, most of the MinJmsfGFP protein pool appeared to participate in the fluorescence recovery $(77 \%)$. When we measured DivIVA-GFP and DivIVA-mNeonGreen dynamics at septal localizations using FRAP, we observed similar mobility (DivIVA GFP $\mathrm{T}_{1 / 2}=128.64 \mathrm{~s}$ and DivIVA-mNeonGreen $\mathrm{T}_{1 / 2}=60.34 \mathrm{~s}$ ). Since the DivIVAGFP expressing strain has an extra copy of $\operatorname{div} / V A$, it seems logical that the recovery time roughly doubles compared to the DivIVA-mNeonGreen expressing strain with only one copy of the gene. 
our own lab using a merodiploid strain already suggested that DivIVA is dynamic [62]. Roughly, two thirds of DivlVA molecules were participating in dynamics.

\section{Interaction of Min proteins influences their dynamics}

To obtain a better understanding of the interactions between Min proteins and to find an explanation for the observed dynamics, we performed FRAP experiments in various genetic knockout backgrounds of Min genes. The Min system is hierarchically assembled with DivIVA recruiting MinJ, which then recruits MinD [58]. In agreement with that, we saw a loss of polar and septal msfGFPMinD localization (BHF025 \& BHF026) when we knocked out minJ or divIVA (data not shown). The same was true for MinJ-msfGFP upon knocking out divIVA (BHF032), further corroborating that DivlVA/MinJ complexes are required for controlled MinD localization. Therefore, we did not include these strains in the FRAP analysis. When $\min C D$ was knocked out in a strain expressing MinJ-msfGFP, the half-time recovery in FRAP dropped from 62s to 30s (Figure 2, Tab. 2, Fig. S6). This behavior indicates direct interaction between the two proteins. We cannot exclude that the phenotype itself impacts the dynamic behavior of MinJ, since cells are elongated and often re-divide after successful cytokinesis [61]. When $\min C D$ was knocked out in a DivIVA-GFP expressing strain (BHF040) however, we could not see any significant difference in fluorescence recovery. Since there is no direct interaction, DivlVA dynamics do not seem to be affected by MinCD directly nor indirectly, which includes the effects of the phenotype of elongated cells. Contrary to that, knocking out $\min J$ sped up recovery of DivIVA-GFP (BHF041) significantly, with a recovery time less than half of the wild type, which was also true for DivIVA-mNeonGreen (BHF027) (Tab. 2, Fig. S6). This is consistent with a direct DivIVA MinJ interaction. Interestingly, there was also an impact on the mobile fraction, which decreased from around two thirds to roughly $40 \%-50 \%$ in both strains. Thus, dynamics are modulated by complex formation reflecting the expected protein hierarchy. MinD recruitment to midcell is fully dependent on DivlVA/MinJ. Since these proteins are only relocating to late stages of septum development, e.g. after a crosswall has started to form, we argue that this geometric change 
200 in the cell is important to redistribute MinD from the poles to midcell and establish a new dynamic

201 steady state at the septum/new pole. This localization of MinD at midcell is lost if either DivlVA or

202 MinJ are deleted, or MinD ATPase activity is abolished, as it can be observed in the G12V and K16A

203 ATPase mutants of MinD [77]. Thus, maintenance of a steady gradient requires ATPase activity and is

204 therefore similar to the E. coli system. Therefore, we aimed to support this hypothesis by mathematical modelling to understand the observed dynamics further.

Previous theoretical studies of the Min system in B. subtilis are sparse. To our knowledge, there is actually only a single theoretical study that has investigated a mechanism for the polar localization of proteins [78]. In this work, the coupled dynamics of DivlVA and MinD are modeled by a reactiondiffusion system in one spatial dimension. Both MinD and DivlVA are considered to diffuse on the membrane and in the cytosol, and cycle between these two compartments by attachment and detachment processes. Membrane-bound MinD is assumed to be stabilized through DivIVA, hence its role is quite different from MinE, which destabilizes membrane-bound MinD. Moreover, it was argued that DivIVA requires the presence of MinD for membrane binding [78]; specifically, that DivlVA binds to and then stabilizes the edges of MinD clusters. Since the model was studied in one spatial dimension, the author accounted for geometric effects only implicitly by reducing the MinD attachment rate near the cell poles. The importance of ATP binding and hydrolysis on MinD activity has been discussed, but disregarded in the model as explicit coupling between cytosol and membrane (bulk-boundary coupling) was not considered. In summary, the model was a first and interplay in shaping protein localization in B. subtilis. 
the idea of geometry sensing put forward in Ref. [79], our model provides a possible mechanism for how proteins sense cell geometry. This mathematical analysis shows that Min polarization and localization is established through a highly dynamic process driven by the ATPase activity of MinD.

This implies Min protein gradients are maintained by genuine nonequilbrium processes and not by thermodynamic binding (chemical equilibrium) of Min proteins to a DivIVA template at the cell poles $[3,8]$.

We study protein dynamics in realistic three-dimensional (3D) cellular geometry, where proteins cycle between cytosol and membrane, and MinD diffuses with diffusion constants, $D_{D}=16 \mu m^{2} / \mathrm{s}$ and, $D_{d}=0.06 \mu \mathrm{m}^{2} / \mathrm{s}$, in the cytosol and on the membrane, respectively. Experimental studies have shown that DivIVA binds preferentially to regions of high negative membrane curvature and that MinJ localization is dependent on the presence of DivIVA [57, 58]. Moreover, MinJ is known to act as an intermediary between DivIVA and MinD [58]. Integrating this information into a mechanistic theoretical model, we consider fully resolved dynamics of MinD (including its ATPase cycle). The biochemical reaction scheme, illustrated in Figure $\mathbf{3} \mathbf{a}$ and $\mathbf{b}$, is based on the following molecular processes: (i) Attachment to and detachment from the membrane with rates $k_{D}=0.068 \mu \mathrm{m} / \mathrm{s}$ and $\tilde{k}_{H}=0.1 \mathrm{~s}^{-1}$ respectively. (ii) A nonlinear recruitment process of cytosolic MinD by membranebound MinD with rate $\tilde{k}_{d D}=0.04 \mu \mathrm{m}^{2} / \mathrm{s}$ (iii) After detachment from the membrane, MinD is in an ADP-bound state and can rebind to the membrane only after nucleotide exchange which occurs at rate $\lambda=6 s^{-1}$. The protein numbers and membrane diffusion of MinD were extracted from our measurements (see Tab. 2 and Supplementary Material ,Tab. S1 and Tab. S2) and the values for the rate constants were estimated from previous work on protein pattern formation $[30,32,34,78]$. The action on DivlVA and MinJ is accounted for effectively through space-dependent recruitment and detachment rates of MinD at membrane areas with a negative curvature; for details please refer to the Methods section (Fig. S7). Specifically, in our computational studies, using finite element 
rate) and that detachment is reduced through stabilization by MinJ-DivIVA complexes (smaller detachment rate). The latter assumption is motivated by experiments, which suggest that DivlVA serves as a scaffold protein $[57,80]$. Under the above conditions, MinD accumulates at both cell poles in a dynamic equilibrium with proteins constantly cycling between cytosol and membrane

(Figure $3 \mathrm{c}$ ). In contrast, in the absence of preferential attachment at the cell poles facilitated by

MinJ-DivlVA complexes, polar localization of MinD becomes unstable and the proteins become preferentially localized in the cell center (again in a dynamic equilibrium state). As can be inferred from Figure $\mathbf{3} \mathbf{c}$, this localization is, however, rather diffuse and covers the whole cell body. Next, we tested whether MinD can be localized at midplane in the presence of MinJ-DivIVA complexes once a septum has formed there. Indeed, emulating the presence of these complexes by an enhanced recruitment and detachment rate localized at the septum, our simulations show that MinD becomes sharply localized at midplane following the transfer of MinJ-DivIVA complexes from the poles to the section).

\section{Single molecule resolution of the Min system reveals cluster formation}

Next, we wanted to test these theoretical predictions concerning a dynamic steady state of MinD

proteins experimentally, using single molecule resolution microscopy. In contrast to a stationary bipolar gradient of Min proteins from the cell poles, as described before $[3,8]$ based on a simple

271 thermodynamic binding of Min proteins to a DivlVA/MinJ template, we expect a dynamic relocalization of Min proteins from the cell pole to the septum. This dynamic steady state would reveal Min components along the entire membrane, including the lateral sites at any time. To achieve the highest possible resolution we used photo-activated light microscopy (PALM). Accordingly, strains expressing Dendra2-MinD (BHF011), MinJ-mNeonGreen (JB40) and DivIVA- 
photoswitchable/photactivatable FPs that can be converted from green to red/activated with UV

light and are hence well suited for PALM [66], mNeonGreen can be used for PALM because of its innate capability to photo-switch [68]. However, it presents some challenges compared to classical photoactivatable FPs as it cannot be pre-bleached and therefore requires more post-processing for reaching a satisfying artifact-free molecule localizations [73]. Nevertheless, all three strains could be successfully imaged in fixed cells with average precisions of 25 to $30 \mathrm{~nm}$ (Figure 4).

Importantly, we observed all Min proteins not only localized to the cell poles, but also as clusters along the membrane and some apparent cytoplasmic localizations. These protein accumulations can be mainly seen along the membrane for MinJ (Figure $\mathbf{4} \mathbf{b}$, middle panel), while a fraction of MinD and DivlVA could be observed in the cytosol (Figure $4 \mathrm{~b}$, left $\&$ right panel). The high abundance of these protein accumulations indicates that recruitment of MinD and DivlVA by existing clusters progresses at higher rates compared to individual membrane binding, which is also reflected in the proposed mathematical model. Double rings of MinJ and DivIVA have been reported previously in 3D structured illumination microscopy [75], which could be observed in late divisional cells in PALM as well (Figure $4 \mathbf{b}$, middle and bottom panel). The active enrichment at the young cell pole is consistent with the theoretical model described above and with a role of the Min system in regulation of cell division rather than protection of cell poles from aberrant cell division [61].

To get a deeper insight into the structure and distribution of the imaged proteins and to confirm clustering, a single-molecule point-based cluster analysis was performed for MinD and DivIVA (Figure

5, Fig. S8, Fig. S9). Unfortunately, MinJ-mNeonGreen imaging did not produce a sufficient amount of events to be analyzed robustly (Fig. S8), as MinJ expression levels are low in comparison and only a small fraction of mNeonGreen molecules blink reliably [73].

In total, we recorded 151,887 events in 48 cells for Dendra2-MinD, while 52,377 events of DivIVA- 
303 prevalence of clusters per cell was higher for MinD (24 clusters per cell) when compared to DivIVA

304 (15 clusters per cell) (Figure $\mathbf{5}$ c). The size of these clusters varied greatly (Figure $\mathbf{5} \mathbf{~ d}$ ), an average size of $72 \mathrm{MinD}$ proteins per cluster was determined, while the average number of DivlVA proteins per cluster was 47 . However, we also observed some very large clusters with up to $1390 \mathrm{MinD}$ proteins and 1198 DivlVA proteins, respectively. Analysis of the relative position of all clusters per cell revealed a high tendency for clusters to form around poles and septa (Figure $\mathbf{5}$ e), where around two-thirds of DivIVA clusters (66\%) and more than half of MinD clusters (59\%) were observed, while the rest was found along the lateral membrane or the cytosol. This correlates well with the idea that most of MinD is recruited to negative membrane curvature (poles and septum) by DivIVA via MinJ. MinD also binds to flat membrane areas where it recruits more MinD from the cytosol. This is less favored due to the lower concentration of MinJ-DivlVA complexes, which is reflected in our simulations and data. Our data also reveal that MinD and DivIVA seem to accumulate, and cytosolic proteins therefore have a higher tendency to bind to existing clusters than to free membrane surfaces. We did not observe a large proportion of MinD dimers and also no homogeneous binding of MinD or DivIVA to the membrane.

The Min reaction network has been extensively studied in various organisms [8, 81]. In E. coli, it was found to be a highly dynamic and self-organizing system capable of pole-to-pole oscillation, a prime example for intracellular protein pattern formation [34]. The two core components in this network, MinE and MinD, cycle between membrane and cytosol and are sufficient to induce robust protein patterns both in vivo and in vitro $[17,18,27,82,83]$. Therefore, it has been puzzling that the Min system in B. subtilis was described to form a rather stationary bipolar gradient from poles to midcell, although MinC and MinD are well conserved. The differences are mainly accredited to the absence of MinE that stimulates ATP hydrolysis and thus membrane detachment of MinD. Instead, the curvature-sensing DivIVA was found to recruit MinCDJ to the negatively curved poles. However, MinC 
and the same study highlights open questions in the current Min model for B. subtilis, pointing out that earlier studies were conducted using strains that artificially overexpress Min network components, thereby possibly masking dynamic populations.

In this study, we analyzed protein dynamics of the B. subtilis Min system based on experiments conducted with native expression levels of fluorescently labeled Min components. Firstly, we found all components to be highly dynamic. MinD had the shortest recovery time of the three investigated proteins, while MinJ and DivIVA were both considerably slower compared to MinD, but in a similar mobile and immobile fractions, where MinD had the highest mobile fraction with almost $80 \%$ of the protein taking part in the recovery. With diffusion coefficients between $0.057 \mu \mathrm{m}^{2} / \mathrm{s}$ and 0.0034 $\mu \mathrm{m}^{2} / \mathrm{s}$, the three proteins were found in an expected range for membrane (-associating) proteins in bacteria [84]. Considering the nature of DivIVA, which binds to the membrane and stabilizes itself at negative curvature, and MinJ as an integral membrane protein, it is not surprising that the cytosolic Min D is around 10 fold faster in recovery. This observation leads to the speculation of a relatively fast exchange of membrane bound MinD proteins at the division septum, considering relative high total protein quantities (Tab. S1) in combination with a large mobile fraction and fast recovery when bleaching these sites. DivlVA total protein numbers were found to be around half of MinD, while MinJ was by far the least abundant Min component. These findings correlate with the corresponding fluorescence intensity and appearance when imaging the respective Min proteins tagged with the same fluorophore during mid-exponential growth (e.g. Fig. S2).

Moreover, knocking out single or multiple components had impact on the dynamics of the respective 
354 We propose a minimal reaction-diffusion model that correctly reproduces qualitative features of

355 MinD localization in B. subtilis. We extracted the parameters for the model from our measurements

356 (protein numbers and diffusion coefficients, Tab. S1 and Tab. 2) and from previous work on

357 intracellular protein pattern formation [30, 32, 34, 79]. The basic assumption of the model is that

358 DivlVA acts as a spatial template for MinJ and MinD, which we accounted for implicitly through a

359 space-dependent recruitment and detachment rate for MinD. From the computational analysis of

360 the model (FEM simulations) we found that localization of MinD to the poles or the division site

361 corresponds to a dynamic equilibrium state of the reaction-diffusion equation. Further, our results

362 show that a geometric effect alone is sufficient to guide MinD to the division site, therefore

363 highlighting the importance of realistic 3D models.

364 Our model can be straightforwardly extended to include the explicit dynamics of DivIVA and MinJ. As

365 the exact reaction network of the Min system in B. subtilis remains elusive, a theoretical model could

366 help in identifying the essential components of Min dynamics. Following the same approach as for

367 the E. coli Min system, reconstitution of the Min system in vitro would also help to dissect the

368 complexity of the system and to make the comparison between experiments and theory even more

369 feasible. We believe that our theoretical approach may serve as a basis for future studies addressing

370 protein dynamics in B. subtilis.

371 We note that the observed dynamics are not compatible with a division-site selection system,

372 because ongoing division is needed for correct localization and dynamics of the Min system in $B$.

373 subtilis. This is in line with data obtained by Elizabeth Harry's lab that deletion of Min proteins does

374 not abolish midcell positioning of the Z-ring in B. subtilis [85] and our own data describing reduced

375 disassembly of Z-rings in absence of the Min system [61]. The model we propose includes a yet

376 unknown protein or mechanism that stimulates MinD-ATP hydrolysis. The uniform hydrolysis rate $k_{H}$

377 in our model was predicted to be similar to the closely related MinD in E. coli, which is stimulated by

378 MinE $[23,27]$. The responsible protein or mechanism has yet to be elucidated, but the presence of 
379 cytosolic and membrane-bound MinD fractions and their respective dynamics as well as the well-

380 conserved ATPase domain argue very convincingly for its existence.

381 Additionally, we investigated the Min components with single-molecule resolution, revealing a strong

382 tendency for cluster formation and these clusters are also found at the lateral sides of the cell

383 membrane. The lateral Min assemblies have not been resolved by conventional light microscopy

384 images and hence the idea of an exclusive polar Min assembly manifested. Clusters of MinD and

385 DivlVA are indeed frequently observed close to poles and midcell. In accordance with the

386 mathematical model, we hence hypothesize that a fraction of MinD will diffuse away from these

387 primary binding sites after recruitment. Most of this fraction will quickly unbind the membrane due

388 to the lack of stabilization, and will be recruited again by DivIVA-MinJ to either pole or septum

389 clusters. Proteins that are part of a cluster will show less exchange or dynamic behavior, further

390 decreasing towards the center, as it can be typically observed in protein clusters [86]. This

391 mechanism could tightly regulate spatio-temporal localization of MinCD and, likewise, aid in

392 transitioning from polar localization to septal localization rapidly upon septum formation, as DivIVA

393 and MinJ would transition to the septum first. Since the current view on the task of the Min system

394 in B. subtilis proposes a role downstream of cell division, all components need to be concentrated at

395 the septum in time to inhibit a second round of division by promoting the disassembly of the division

396 apparatus [61].

397

398

399

400

401

402

\section{Acknowledgments}

This research was supported by the Deutsche Forschungsgemeinschaft within the Transregio Collaborative Research Center (TRR 174) "Spatiotemporal Dynamics of Bacterial Cells" (project P03 to E.F. and P05 to M.B.).We thank the members of the M.B. lab for discussions, feedback and comments on the manuscript. 
404

405

406

407

408

409

410

411

412

\section{Author Contributions}

M.B. and E.F. conceived the study, H.F. constructed the strains, performed the in vivo experiments incl. microscopy and analyzed the data, L.W. and E.F. developed the theoretical model and performed the mathematical analysis. All authors wrote the manuscript.

\section{Declaration of Interests}

The authors declare no competing interests.

\section{Tables}

Tab. 1: Phenotypic characterization of relevant strains. For determination of the growth rate constant $\mu$ the optical density at $600 \mathrm{~nm}$ of exponentially growing cells was measured. Cell lengths and the ratio of minicells were determined microscopically using Fiji, with $n \geq 200$. Strains were grown in independent triplicates, with differences reflected in the standard deviation.

\begin{tabular}{lllll}
\hline Strain & Description of strain & Mean growth rate & Mean cell length & Minicells \\
& & constant $[\mu]$ & {$[\mu \mathrm{m}]$} & {$[\%]$} \\
\hline $\mathbf{1 6 8}$ & Wild type & $0.53 \pm 0.004$ & $3.106 \pm 0.773$ & 0.3 \\
\hline $\mathbf{3 3 0 9}$ & $\Delta \operatorname{minCD}$ & $0.45 \pm 0.021$ & $7.639 \pm 2.702$ & 45.8 \\
\hline RD021 & $\Delta$ minJ & $0.51 \pm 0.049$ & $6.645 \pm 2.022$ & 13.8 \\
\hline $\mathbf{4 0 4 1}$ & $\Delta$ div/VA & $0.46 \pm 0.020$ & $8.128 \pm 3.404$ & 29.6 \\
\hline BHF011 & Dendra2-MinD & $0.49 \pm 0.004$ & $2.664 \pm 0.607$ & 0.9 \\
\hline BHF017 & msfGFP-MinD & $0.55 \pm 0.004$ & $4.221 \pm 1.036$ & 9.1 \\
\hline JB38 & MinJ-Dendra2 & $0.51 \pm 0.006$ & $3.437 \pm 1.056$ & 0 \\
\hline BHF007 & MinJ-msfGFP & $0.57 \pm 0.013$ & $3.375 \pm 0.755$ & 0.3 \\
\hline JB40 & MinJ-mNeonGreen & $0.57 \pm 0.002$ & $3.156 \pm 0.673$ & 0 \\
\hline JB36 & DivlVA-Dendra2 & $0.50 \pm 0.007$ & $4.327 \pm 0.917$ & 8.0 \\
\hline
\end{tabular}


bioRxiv preprint doi: https://doi.org/10.1101/2020.04.29.068676; this version posted April 30, 2020. The copyright holder for this preprint (which was not certified by peer review) is the author/funder, who has granted bioRxiv a license to display the preprint in perpetuity. It is made available under aCC-BY-NC-ND 4.0 International license.

\begin{tabular}{|c|c|c|c|c|}
\hline 1803 & DivIVA-GFP & $0.45 \pm 0.021$ & $3.309 \pm 0.733$ & 1.1 \\
\hline BHF028 & DivIVA-mNeon Green & $0.54 \pm 0.029$ & $5.419 \pm 1.351$ & 5.3 \\
\hline JB37 & DivIVA-PAmCherry & $0.51 \pm 0.019$ & $4.346 \pm 1.105$ & 3.3 \\
\hline
\end{tabular}

418

419 
bioRxiv preprint doi: https://doi.org/10.1101/2020.04.29.068676; this version posted April 30,2020. The copyright holder for this preprint (which

was not certified by peer review) is the author/funder, who has granted bioRxiv a license to display the preprint in perpetuity. It is made available under aCC-BY-NC-ND 4.0 International license.

420 Tab. 2: Results of FRAP analysis for the Min proteins in different genetic backgrounds.

\begin{tabular}{|c|c|c|c|c|}
\hline $\begin{array}{l}\text { Protein and genetic } \\
\text { background }\end{array}$ & Fluorophore & $\begin{array}{l}\text { Diffusion coefficient } \\
{\left[\mu \mathrm{m}^{2} * 10^{-3} * \mathrm{~s}^{-1}\right]}\end{array}$ & $\begin{array}{l}\text { Half-Time } \\
\text { Recovery [s] }\end{array}$ & $\begin{array}{l}\text { Mobile } \\
\text { Fraction }\end{array}$ \\
\hline MinD in wild type & msfGFP & $57.78 \pm 10.05$ & $7.55 \pm 1.31$ & $0.79 \pm 0.06$ \\
\hline MinJ in wild type & msfGFP & $7.19 \pm 2.27$ & $62.35 \pm 19.71$ & $0.77 \pm 0.14$ \\
\hline MinJ in $\triangle \min C D$ & msfGFP & $14.46 \pm 9.54$ & $30.18 \pm 19.92$ & $0.75 \pm 0.07$ \\
\hline DivIVA in wild type & GFP & $3.39 \pm 0.82$ & $128.64 \pm 30.92$ & $0.65 \pm 0.23$ \\
\hline DivIVA in $\triangle \min C D$ & GFP & $3.74 \pm 1.36$ & $116.79 \pm 42.40$ & $0.68 \pm 0.26$ \\
\hline DivIVA in $\Delta \min J$ & GFP & $8.57 \pm 4.43$ & $50.94 \pm 26.35$ & $0.49 \pm 0.15$ \\
\hline DivIVA in $\triangle \min C D J$ & GFP & $4.98 \pm 2.93$ & $87.67 \pm 51.55$ & $0.61 \pm 0.27$ \\
\hline DivlVA in wild type & mNeonGreen & $7.23 \pm 1.99$ & $60.34 \pm 16.57$ & $0.64 \pm 0.23$ \\
\hline DivlVA in $\triangle \min C D$ & mNeonGreen & $6.88 \pm 2.76$ & $63.43 \pm 25.41$ & $0.67 \pm 0.20$ \\
\hline DivlVA in $\Delta \mathrm{min} J$ & mNeonGreen & $18.01 \pm 3.22$ & $24.40 \pm 4.33$ & $0.39 \pm 0.11$ \\
\hline DivIVA in $\triangle \min C D J$ & mNeonGreen & $9.47 \pm 4.26$ & $46.07 \pm 20.71$ & $0.66 \pm 0.23$ \\
\hline
\end{tabular}


Tab. 3: Oligonucleotides used in this study.

\begin{tabular}{|c|c|}
\hline Oligo name & Sequence (5' to $\left.3^{\prime}\right)$ \\
\hline bsarem1 & TTTGGTCTCAGGTTCTCGCGGTATCATTGCAGC \\
\hline bsarem2 & TTTGGTCTCAAACCACGCTCACCGGCTCCAG \\
\hline HF0061 & GTCGGTCTCAACTAGAATTCGTAATCATGGTCATAGCTG \\
\hline HF0062 & CTCGGTCTCATCGGAAGCTTGGCACTGGC \\
\hline HF0037 & TATGGTCTCCCCGAGTTCATTCTATTGACAGTGAAGTC \\
\hline HF0038 & CTAGGTCTCTCTCCTTCACATTCCTCCCTCAAG \\
\hline HF0040 & AATGGTCTCTGGAGGGGTGAAAGGATGTACTTA \\
\hline HF0041 & TTTGGTCTCGCGAATAATTGAGAGAAGTTTCTATAG \\
\hline HF0042 & GGAGGTCTCTTTCGATGAACACCCCGGGAATTAAC \\
\hline HF0043 & CACGGTCTCCCATTCCACACCTGGCTGGGCAGG \\
\hline HF0044 & ACGGGTCTCAAATGGGTTGGGTGAGGCTATCGTAATAAC \\
\hline HF0045 & CGGGGTCTCTTAGTCAATATTTTCCTCTTGGTCCAGC \\
\hline HF0065 & GGAGGTCTCTTTCGATGGGTACCCTGCAGATG \\
\hline HF0066 & CACGGTCTCCCATTTTTGTAGAGCTCATCCATGC \\
\hline G40 & CTAGGTCTCTCCGATGTCGGATTTGGACA \\
\hline G41 & TATGGTCTCCCTCCTGATCCCGAAGCGAC \\
\hline HF0029 & AATGGTCTCTGGAGGGATGGGTACCCTGCAGATG \\
\hline HF0030 & TTTGGTCTCGCGAATTTGTAGAGCTCATCCATGC \\
\hline G20 & AATGGTCTCTGGAGGGATGAACACCCCGGGAATTAAC \\
\hline G21 & TTTGGTCTCGCGAATTACCACACCTGGCT \\
\hline G36 & GGAGGTCTCTTTCGGGGTGAAAGGATGTACTTA \\
\hline G37 & CACGGTCTCCCATTTAATTGAGAGAAGTT \\
\hline G42 & ACGGGTCTCAAATGGGAAGGCAGCCCGGCACCGCAGG \\
\hline G43 & CGGGGTCTCTTAGTCCATGATGGCTGGTG \\
\hline
\end{tabular}


bioRxiv preprint doi: https://doi.org/10.1101/2020.04.29.068676; this version posted April 30, 2020. The copyright holder for this preprint (which was not certified by peer review) is the author/funder, who has granted bioRxiv a license to display the preprint in perpetuity. It is made available under aCC-BY-NC-ND 4.0 International license.

\begin{tabular}{ll}
\hline HF0077 & AATGGTCTCTGGAGGGATGGTGAGCAAGGGCG \\
HF0078 & TTTGGTCTCGCGAATTACTTGTACAGCTCGTCCATG \\
G32 & ACGGGTCTCAAATGGGATTCTCTGATTATCT \\
G33 & CGGGGTCTCTTAGTATCGGGAAATCTGTT \\
G34 & CTAGGTCTCTCCGAGAATTCCTAGCCCAAGTCAG \\
G35 & TATGGTCTCCCTCCTTCCTTTCCTCAAA \\
\hline
\end{tabular}

424

425 
bioRxiv preprint doi: https://doi.org/10.1101/2020.04 29.068676; this version posted April 30, 2020. The copyright holder for this preprint (which

was not certified by peer review) is the author/funder, who has granted bioRxiv a license to display the preprint in perpetuity. It is made available under aCC-BY-NC-ND 4.0 International license.

Tab. 4: Plasmids used in this study.

\begin{tabular}{|c|c|c|}
\hline Plasmid & Characteristic & Reference/Source \\
\hline pUC18 & lac $Z \alpha, p M B 1$ ori, bla $\left(\mathrm{Ap}^{\mathrm{R}}\right)$ & Norrander et al, 1983 \\
\hline pUC18mut & pUC18 with mutated Bsal site in bla & Laboratory collection \\
\hline pDendra2-N & pUC ori,SV4O ori, PCMVIE, aph3-A3 & Evrogen \\
\hline pNCS-mNeonGreen & pUC ori, SV40 ori, bla $\left(\mathrm{Ap}^{\mathrm{R}}\right)$ & Allele Biotechnology \\
\hline pHJS105 & $\begin{array}{l}\text { amyE-integration vector containing Pxyl- } \\
\text { msfgfp-MCS, spc bla }\end{array}$ & Jahn et al, 2015 \\
\hline pHF01 & pUC18mut-minDup-aad9-Dendra2-minD & This study \\
\hline pHF02 & pUC18mut-minDup-aad9-msfGFP-minD & This study \\
\hline pHF03 & pUC18mut-minJ-msfGFP-aad9-minJdown & This study \\
\hline pHF04 & pUC18mut-minJ-mNG-aad9-minJdown & This study \\
\hline pHF05 & pUC18mut-divIVA-mNG-aad9-divIVAdown & This study \\
\hline pHF06 & pUC18mut-minJ-Dendra2-aad9-minJdown & This study \\
\hline pHF07 & pUC18mut-divIVA-Dendra2-aad9-divIVAdown & This study \\
\hline
\end{tabular}

427 
Tab. 5: Strains used in this study.

\begin{tabular}{|c|c|c|}
\hline Strain & Relevant features or genotype & Reference/Source \\
\hline \multicolumn{3}{|c|}{ B. subtilis } \\
\hline 168 & $\operatorname{trpC2}$ & Laboratory collection \\
\hline 3309 & $\min C D:: a p h 3-A 3$ & Wu and Errington, 2004 \\
\hline RD021 & $\min J:: t e t$ & Bramkamp et al, 2008 \\
\hline 4041 & divIVA::tet & Bramkamp et al, 2008 \\
\hline SB075 & $\min C D:: e r m, \operatorname{minJ}:: t e t$ & Laboratory collection \\
\hline BHF011 & $\min D:: a a d 9-D e n d r a 2-\min D$ & This study, pHF01 -> 168 \\
\hline BHF017 & $\min D:: a a d 9-m s f G F P-\min D$ & This study, pHF02 -> 168 \\
\hline BHF025 & $\min D:: a a d 9-m s f G F P-\min D, \min J:: t e t$ & This study, pHF02 -> RD021 \\
\hline BHF026 & $\min D:: a a d 9-m s f G F P-\min D$, divIVA::tet & This study, pHFO2 -> 4041 \\
\hline JB038 & $\min J:: \min J-D e n d r a 2-a a d 9$ & This study, pHF06 -> 168 \\
\hline BHF007 & $\min J:: \min J-m s f G F P-a a d 9$ & This study, pHF03 -> 168 \\
\hline BHF015 & $\operatorname{minJ}:: \min J-m s f G F P-a a d 9, \operatorname{minCD}:: a p h 3$ & This study, pHF03 -> 3309 \\
\hline BHF032 & minJ::minJ-msfGFP-aad9, 23ivIVA::tet & This study, pHF03 -> 4041 \\
\hline JB40 & $\operatorname{minJ}:: \min J-m N e o n G r e e n-a a d 9$ & This study, pHF04 -> 168 \\
\hline JB36 & divIVA::divIVA-Dendra2-aad9 & This study, pHF07 -> 168 \\
\hline BHF028 & divIVA::divIVA-mNeonGreen-aad9 & This study, pHF05 -> 168 \\
\hline BHF036 & divIVA::divIVA-mNeonGreen-aad9, min & This study, pHF05 -> 3309 \\
\hline
\end{tabular}

A3

\begin{tabular}{l|l|l}
\hline BHF027 & divIVA::divIVA-mNeonGreen-aad9,minJ::tet & This study, pHF05 -> RD021 \\
\hline BHF037 & divIVA::divIVA-mNeonGreen-aad9, minCD::erm, & This study, pHF05 -> SB075 \\
& minJ::tet & Thomaides et al, 2001 \\
\hline 1803 & divIVA::divIVA-GFP-cat & This study, 1803-> 3309 \\
\hline BHF040 & divIVA::divIVA-GFP-cat, minCD::aph3-A3 & \\
\hline
\end{tabular}


bioRxiv preprint doi: https://doi.org/10.1101/2020.04.29.068676; this version posted April 30, 2020. The copyright holder for this preprint (which was not certified by peer review) is the author/funder, who has granted bioRxiv a license to display the preprint in perpetuity. It is made available under aCC-BY-NC-ND 4.0 International license.

\begin{tabular}{l|l|l}
\hline BHF041 & divIVA::divIVA-GFP-cat, minJ::tet & This study, 1803-> RD021 \\
\hline BHF042 & divIVA::divIVA-GFP-cat, minCD::erm, minJ::tet & This study, 1803-> SB075 \\
\hline JB37 & divIVA::divIVA-PAmCherry-aad9 & Stockmar et al, 2018 \\
\hline
\end{tabular}

\section{E. coli}

\begin{tabular}{l|l|l} 
NEB Turbo & $\mathrm{F}^{\prime}$ proA $^{+} B^{+}$Iacl $^{q} \triangle l a c Z M 15 /$ fhuA2 $\triangle($ lac-proAB $)$ & New England Biolabs \\
& glnV galK16 galE15 $R(z g b-210:: T n 10)$ Tet $^{S}$ endA1 & \\
& thi-1 $\triangle($ hsdS-mcrB $) 5$
\end{tabular}

430 
bioRxiv preprint doi: https://doi.org/10.1101/2020.04.29.068676; this version posted April 30, 2020. The copyright holder for this preprint (which

was not certified by peer review) is the author/funder, who has granted bioRxiv a license to display the preprint in perpetuity. It is made available under aCC-BY-NC-ND 4.0 International license.

432 Tab. 6: Filter parameters for PALM imaging of the different strains. Filters were chosen according to 433 the fluorophore behavior in PALM to eliminate background and signal of fluorescent beads from the 434 results.

\begin{tabular}{lcc}
\hline Strain/FP & Filter: PSF width at half maximum & Filter: Photon Number \\
\hline Dendra2-MinD & $70-160$ & $70-250$ \\
MinJ-mNeonGreen & $70-160$ & $70-300$ \\
DivIVA-PAmCherry & $60-170$ & $50-500$ \\
\hline
\end{tabular}

435

436 


\section{Material and Methods:}

438

439

440

441

442

443

444

445

446

447

448

449

450

451

452

453

454

455

456

457

458

459

460

\section{Bacterial strains, plasmids and oligonucleotides}

The oligonucleotides, plasmids and strains used in this study are listed in Tab. 3, Tab. 4 and Tab. 5, respectively. E. coli NEB Turbo was used to amplify and maintain plasmids.

\section{Strain construction}

Golden Gate assembly

Fragments for Golden Gate assembly were amplified from B. subtilis 168 (trpC2) genomic DNA or template plasmids via PCR with the respective primers containing directional overhangs (Tab. 3). The vector pUC18mut was also amplified via PCR to introduce Bsal restriction sites and allow subsequent digestion of circular PCR template with Dpnl, which only cuts methylated DNA. Plasmid construction was verified via individual control digestion and DNA sequencing. Correct plasmids were transformed into $B$. subtilis 168 with the respective genetic background (Tab. 5) and selected for the introduced resistance (Tab. 4). Resistant candidates were confirmed with PCR and microscopy.

pHF01 [pUC18mut-minDup-aad9-Dendra2-minD] was created by a Golden Gate assembly of 5 fragments: 1) PCR with primers HF0061 and HF0062 with pUC18mut as template (yielding a linear pUC18mut; 2) PCR with primers HF0037 and HF0038 and 168 genomic DNA (containing the region upstream of $\min D$ ); 3) PCR with primers HF0040 and HF0041 and JB40 genomic DNA (containing the spectinomycin adenyltransferase aad9); 4) PCR with primers HF0042 and HF0043 and pDendra2-N plasmid DNA (containing the Dendra2 gene); 5) PCR with primers HF0044 and HF0045 and 168 genomic DNA (containing the $\mathrm{N}$-terminal region of $\min D$ ).

pHF02 [pUC18mut-minDup-aad9-msfGFP-minD] was created by a Golden Gate assembly of 5 fragments: 1) PCR with primers HF0061 and HF0062 with pUC18mut as template (yielding a linear pUC18mut; 2) PCR with primers HF0037 and HF0038 and 168 genomic DNA (containing the region upstream of $\min D$ ); 3) PCR with primers HF0040 and HF0041 and JB40 genomic DNA (containing the 
461 spectinomycin adenyltransferase aad9); 4) PCR with primers HF0065 and HF0066 and pHJS105

462 (containing the msfGFP gene); 5) PCR with primers HF0044 and HF0045 and 168 genomic DNA

463 (containing the $\mathrm{N}$-terminal region of $\min D$ ).

pHF03 [pUC18mut-minJ-msfGFP-aad9-minJdown] was created by a Golden Gate assembly of 5 fragments: 1) PCR with primers HF0061 and HF0062 with pUC18mut as template (yielding a linear pUC18mut; 2) PCR with primers G40 and G41 and 168 genomic DNA (containing the C-terminal region of $\min J)$; 3) PCR with primers HF0029 and HF0030 and pHJS105 (containing the msfGFP gene); 4) PCR with primers $G 36$ and G37 and JB40 genomic DNA (containing the spectinomycin adenyltransferase aad9); 5) PCR with primers G42 and G43 and 168 genomic DNA (containing the region downstream of $\min \lrcorner$ ).

pHF04 [pUC18mut-minJ-mNG-aad9-minJdown] was created by a Golden Gate assembly of 5

fragments: 1) PCR with primers HF0061 and HF0062 with pUC18mut as template (yielding a linear pUC18mut; 2) PCR with primers G40 and G41 and 168 genomic DNA (containing the C-terminal region of $\min$ ); 3) PCR with primers HF0077 and HF0078 and pNCS-mNeonGreen DNA (containing the mNeonGreen gene); 4) PCR with primers G36 and G37 and JB40 genomic DNA (containing the spectinomycin adenyltransferase aad9); 5) PCR with primers G42 and G43 and 168 genomic DNA

477 (containing the region downstream of $\min J)$.

pHF05 [pUC18mut-divIVA-mNG-aad9-divIVAdown] was created by a Golden Gate assembly of 5 fragments: 1) PCR with primers HF0061 and HF0062 with pUC18mut as template (yielding a linear 
pHF06 [pUC18mut-minJ-Dendra2-aad9-minJdown] was created by a Golden Gate assembly of 5

fragments: 1) PCR with primers HF0061 and HF0062 with pUC18mut as template (yielding a linear pUC18mut; 2) PCR with primers G40 and G41 and 168 genomic DNA (containing the C-terminal region of $\min J$ ); 3) PCR with primers G20 and G21 and pDendra2-N plasmid DNA (containing the Dendra2 gene); 4) PCR with primers $G 36$ and G37 and JB40 genomic DNA (containing the spectinomycin adenyltransferase aad9); 5) PCR with primers G42 and G43 and 168 genomic DNA (containing the region downstream of $\min J$ ).

pHF07 [pUC18mut-divIVA-Dendra2-aad9-divIVAdown] was created by a Golden Gate assembly of 5 region of div/VA); 3) PCR with primers G20 and G21 and pDendra2-N plasmid DNA (containing the (containing the region downstream of $\operatorname{div} / V A$ ).

B. subtilis was grown on nutrient agar plates using commercial nutrient broth and $1.5 \%(\mathrm{w} / \mathrm{v})$ Agar at $37^{\circ} \mathrm{C}$ overnight. To reduce inhibitory effects, antibiotics were only used for transformations and when indicated, since allelic replacement is stable after integration (chloramphenicol $5 \mu \mathrm{g} \mathrm{ml}^{-1}$, tetracycline $10 \mu \mathrm{gl}^{-1}$, kanamycin $5 \mu \mathrm{g} \mathrm{ml}^{-1}$, spectinomycin $100 \mu \mathrm{g} \mathrm{ml}^{-1}$, erythromycin $1 \mu \mathrm{g} \mathrm{ml^{-1 }}$ ).

For growth curves, $B$. subtilis was inoculated to an $\mathrm{OD}_{600} 0.05$ from a fresh overnight culture and grown in LB (lysogeny broth) $\left[10 \mathrm{gl}^{-1}\right.$ tryptone, $10 \mathrm{~g} \mathrm{I}^{-1} \mathrm{NaCl}$ and $5 \mathrm{~g} \mathrm{I}^{-1}$ yeast extract] at $37^{\circ} \mathrm{C}$ with

507 aeration in baffled shaking flasks $(200 \mathrm{rpm})$ to $\mathrm{OD}_{600} 1$. Subsequently, cultures were diluted to $\mathrm{OD}_{600}$ $508 \quad 0.1$ in fresh LB and measured every hour for at least 6 hours. 
509 For microscopy, B. subtilis was inoculated to an $\mathrm{OD}_{600} 0.05$ from a fresh overnight culture and grown 510 in MD medium - a modified version of Spizizen Minimal Medium [87] - at $37^{\circ} \mathrm{C}$ with aeration in

511 baffled shaking flasks $\left(200 \mathrm{rpm}\right.$ ) to $\mathrm{OD}_{600} 1 . \mathrm{MD}$ medium contains $10.7 \mathrm{mg} \mathrm{ml}^{-1} \mathrm{~K}_{2} \mathrm{HPO}_{4}, 6 \mathrm{mg} \mathrm{ml}^{-1}$ $512 \mathrm{KH}_{2} \mathrm{PO}_{4}, 1 \mathrm{mg} \mathrm{ml}^{-1} \mathrm{Na}_{3}$ citrate, $20 \mathrm{mg} \mathrm{m}^{-1}$ glucose, $20 \mathrm{mg} \mathrm{ml}^{-1}$ L-tryptophan, $20 \mathrm{mg} \mathrm{ml}^{-1}$ ferric 513 ammonium citrate, $25 \mathrm{mg} \mathrm{ml}^{-1} \mathrm{~L}$-aspartate and $0.36 \mathrm{mg} \mathrm{ml}^{-1} \mathrm{MgSO}_{4}$ and was always supplemented with $1 \mathrm{mg} \mathrm{ml}^{-1}$ casamino acids. Subsequently, cultures were diluted to $\mathrm{OD}_{600} 0.1$ in fresh MD medium and grown to $\mathrm{OD}_{600} 0.5$ (exponential phase).

516 For epifluorescence and time-lapse imaging (e.g. FRAP), B. subtilis cells were mounted on pre517 warmed $1.5 \% \mathrm{MD}$ agarose pads, sealed with paraffin and incubated $10 \mathrm{~min}$ at $37^{\circ} \mathrm{C}$ before 518 microscopic analysis. When used, FM4-64 dye was added to the agarose pad before polymerization 519 (1 $\mu \mathrm{M}$ final).

520 For PALM imaging, a $0.5 \mathrm{ml}$ portion of $B$. subtilis cells were fixed by addition of formaldehyde (1.5\% $521(\mathrm{w} / \mathrm{v})$ final concentration) and incubated for $20 \mathrm{~min}$ at $37^{\circ} \mathrm{C}$. Subsequently, cells were washed ( $1 \mathrm{~min}$, $5225000 \mathrm{rpm})$, resuspended in fresh MD supplemented with $10 \mathrm{mM}$ glycine to stop the crosslinking 523 reaction and incubated for $10 \mathrm{~min}$ at $37^{\circ} \mathrm{C}$. Then, cells were washed 2 more times with $\mathrm{MD}$ containing $52410 \mathrm{mM}$ glycine. In a final washing step, the pellet was resuspended in $50 \mu \mathrm{l}$ of MD with $10 \mathrm{mM}$ glycine 525 to reach higher cell density. Cells were mounted on chambered coverslips ( $\mu$-slide 8 well, Ibidi) 526 containing $200 \mu \mathrm{MD}$ with $10 \mathrm{mM}$ glycine, which were pretreated for $30-60$ min with $0.1 \%$ Poly-L527 lysine and successively washed 3 times with MD containing $10 \mathrm{mM}$ glycine. Furthermore, TetraSpeck 528 microspheres (100 nm, ThermoFisher) were added in a dilution that results in about 3-10 beads per 529 field of view. To help sedimentation of cells and beads and to reach a uniform attachment to the 530 glass surface, the chambered coverslip was centrifuged at $4000 \mathrm{rpm}$ for $10 \mathrm{~min}$ in a bucket-swing 531 rotor (Eppendorf). 
533 To confirm the presence of full-length protein fusions and for quantitative analysis, B. subtilis strains were inoculated from an overnight culture to $\mathrm{OD}_{600} 0.05$ in the morning, and grown to $\mathrm{OD}_{600} 0.5$ in 10 $\mathrm{ml} \mathrm{LB}$ medium (MD for quantitative studies) at $37^{\circ} \mathrm{C}$. Cells were then diluted $1 / 10$ and grown again to mid-exponential phase $\left(\mathrm{OD}_{600} 0.5\right)$. Cultures were centrifuged at $13.000 \mathrm{rpm}$ for 1 minute, washed once with lysis buffer (10 mM Tris, pH 7.5, $150 \mathrm{mM} \mathrm{NaCl}, 500 \mu \mathrm{M}$ EDTA, $1 \mathrm{mM}$ PMSF), and resuspended in lysis buffer with additional $10 \mathrm{mg} / \mathrm{ml}$ lysozyme (Sigma-Aldrich), $10 \mu \mathrm{g} / \mathrm{ml}$ DNAse I (Roche) and $100 \mu \mathrm{g} / \mathrm{ml}$ RNAse A (Roche), concentrating the sample to $\mathrm{OD}_{600} 30$. After incubation at $37^{\circ} \mathrm{C}$ for 20 minutes, the sample was briefly vortexed to crack remaining intact cells. $30 \mu \mathrm{l}$ of sample was then mixed with $10 \mu$ l of 4x SDS-PAGE loading buffer (200 mM Tris-HCL pH6.8, 400 mM DTT. 8\% SDS. $0,4 \%$ bromophenol blue and $40 \%$ glycerol). For typhoon imaging and subsequent western blotting, samples were incubated for either $20 \mathrm{~min}$ at room temperature, while some samples meant exclusively for western blotting were incubated at $95^{\circ} \mathrm{C}$ for 10 minutes for full denaturation (indicated in Fig. S4) 10 or $20 \mu \mathrm{l}$ of sample were then separated by SDS Page in $12 \%$ Bis-Tris gels. For visualization of green fluorescent fusions, gels were imaged in a Typhoon Trio (GE Healthcare; PMT 600-800, Excitation $488 \mathrm{~nm}$, Emission $526 \mathrm{SP}$ ). For western blotting, proteins were blotted onto 0.2 $\mu \mathrm{m}$ polyvinylidene difluoride (PVDF) membranes. Proteins were visualized via anti-mCherry (polyclonal), anti-mNG (monoclonal) or anti-Dendra (polyclonal) antibodies, respectively.

To quantify Dendra2-fusions of MinD, MinJ and DivlVA via in-gel fluorescence, three biological triplicates were prepared and imaged as described above, while avoiding oversaturation. The total number of MinD molecules was taken from a publication that utilized targeted mass spectrometry to determine absolute protein amounts of $B$. subtilis at mid-exponential phase in minimal medium with glucose [76]. Relative quantification was then performed using ImageJ by measuring and comparing intensity of the bands. 
557 For strain characterization, microscopy images were taken on a Zeiss Axio Observer Z1 microscope equipped with a Hamamatsu OrcaR ${ }^{2}$ camera using a Plan-Apochromat 100×/1.4 Oil Ph3 objective (Zeiss). Dendra2, GFP, msfGFP and mNeonGreen fluorescence was visualized with filterset $38 \mathrm{HE}$ eGFP shift free (Zeiss) and FM4-64 membrane dye was visualized with filterset 63 HE mCherry (Zeiss). acquired with Zen software (Zeiss).

For FRAP experiments a Delta Vision Elite (GE Healthcare, Applied Precision) equipped with an Insight SSI ${ }^{\mathrm{TM}}$ illumination, an X4 laser module and a CoolSnap HQ2 CCD camera was used. Images were taken with a 100×oil PSF U-Plan S-Apo 1.4 NA objective. A four color standard set InsightSSI unit with $\mathrm{nm}$ ); single band pass emission wavelengths (DAPI 435/48 nm, FITC 525/48 nm, TRITC 597/45 nm, Cy5 679/34 nm) and a suitable polychroic for DAPI/FITC/TRITC/Cy5 were used. GFP, msfGFP and mNeonGreen were visualized using FITC settings and exposure times between $0.1 \mathrm{~s}$ (msfGFP, GFP) and $0.2 \mathrm{~s}$ (mNeonGreen). Bleaching was performed using a $488 \mathrm{~nm}$ laser ( $50 \mathrm{~mW}$ ) with $10 \%$ power and a $0.005-0.01 \mathrm{~s}$ pulse. Frequency of acquisition and total amount of images were chosen according to the individual recovery times after initial testing with various settings.

Analysis of the images was performed using ImageJ $1.51 \mathrm{~s}$. The corrected total cell fluorescence

574 (CTCF) was calculated according to following formula: CTCF = Integrated Density-(Area of selected cell X Mean fluorescence of unspecific background readings) [88] .For FRAP experiments unspecific background was subtracted for every ROI (see above). The CTCF of the septa was divided by the CTCF of the whole cell to account for photobleaching during acquisition. The respective quotient of the unbleached spot was always set as 1 for normalization. Since $B$. subtilis keeps growing during timelapse experiments like FRAP, the bleached spot moves in the field of view as cells elongate.

580 Therefore, a macro in Fiji was created to dynamically follow and center the bleached spot through 581 the frames of acquisition without any bias, which resulted in more precise FRAP curves. To determine 
582 half-time recovery and mobile/immobile fractions, the FRAP curve from the normalized recovery

583 values was fitted to an exponential equation: determine halftime recovery (Eq. 2):

$$
t_{\text {half }}=\frac{\ln 0.5}{-\tau}
$$

where $t_{\text {half }}$ is the halftime recovery and $\tau$ the fitted parameter. Diffusion coefficients were then calculated with the following formula:

according to Axelrod et al., 1976 [89] - where $D$ is the diffusion coefficient, $w$ is the radius of the circular laser beam and $\tau_{1 / 2}$ is the time when fluorescence recovery reaches half height of total recovery. To estimate the bleaching spot radius, cells expressing cytosolic GFP were fixed with $1.5 \%$ formaldehyde $(\mathrm{v} / \mathrm{v})$ as described above, mounted on agarose pads, bleached at laser powers of $10 \%$ to $100 \%$ in increments of $10 \%$ and imaged right after bleaching. The radius was measured in Image J and averaged per triplicate to calculate the function of bleach radius over laser power. Graphs and statistics were created in R 3.3.1 [90] utilizing the packages ggplot2 [91] and nlstools [92].

The setup of our mathematical model is based on previous approaches for intracellular protein dynamics [30, 32, 34, 79]. Specifically, we present a minimal model to account for DivlVA mediated MinD localization. The model includes the following set of biochemical reactions: (i) attachment of MinD-ATP (with volume concentration $u_{D T}$ ) from the bulk to the membrane with constant rate $k_{D}$; (ii) recruitment of bulk MinD-ATP to the membrane by membrane-bound MinD (with areal concentration $u_{d}$ ) with rate $k_{d D}$; (iii) hydrolysis and detachment of membrane-bound MinD into bulk 
607

MinD-ADP $\left(u_{D D}\right)$ with rate $k_{H}$; (iv) reactivation of bulk MinD-ADP by nucleotide exchange to MinDATP with rate $\lambda$. The system of ensuing reaction-diffusion equations reads

$$
\partial_{t} u_{D D}=D_{D} \nabla_{c}^{2} u_{D D}-\lambda u_{D D}
$$

(Eq. 4

a)

$$
\partial_{t} u_{D T}=D_{D} \nabla_{c}^{2} u_{D T}+\lambda u_{D D}
$$

(Eq. 4

b)

$$
\partial_{t} u_{d}=D_{d} \nabla_{m}^{2} u_{d}+\left(k_{D}+k_{d D} u_{d}\right) u_{D T}-k_{H} u_{d}
$$

where the subscript $c$ or $m$ denotes that the nabla operator acts in the bulk or on the membrane, respectively. These equations are coupled through nonlinear reactive boundary conditions at the membrane surface stating that the biochemical reactions involving both membrane-bound and bulk proteins equal the diffusive flux onto and off the membrane:

$$
\left.D_{D} \nabla_{n} u_{D D}\right|_{m}=k_{H} u_{d}
$$

(Eq. 5

a)

$$
\left.D_{D} \nabla_{n} u_{D T}\right|_{m}=-\left(k_{D}+k_{d D} u_{d}\right) u_{D T}
$$

(Eq. 5

b)

Here, the subscript $n$ denotes that we take the nabla operator acting along the outward normal vector of the boundary (membrane). The set of reaction-diffusion equations conserve the total mass of MinD. Hence, the total particle number $N_{D}$ of MinD obeys the relation

$$
N_{D}=\int_{\Omega}\left(u_{D D}+u_{D T}\right) d V+\int_{\partial \Omega} u_{d} d S
$$

We simulated the set of reaction-diffusion equations in a spherocylindrical geometry in threedimensional space (3D) using the Finite-Element software COMSOL v5.3a; for an illustration of the geometry used see Fig. S7. The length and height were set to typical values known for B. subtilis cells, $L=2.8 \mu \mathrm{m}$ and $h=0.85 \mu \mathrm{m}$, respectively. The mean total density of MinD was set to $[\operatorname{MinD}]=$ $2450 \mu^{-3}$ for all simulations (see Tab. S2) We assume that, in addition to MinD self-recruitment, MinJ recruits MinD-ATP from the bulk to the membrane and that membrane-bound MinD is stabilized by DivIVA-MinJ complexes on the membrane. We model the interaction of MinD with MinJ and DivIVA implicitly through space-dependent recruitment and detachment rates. To this end, we assume that the recruitment rate is amplified by a factor $\alpha$ and that the detachment rate is reduced by a factor $\beta$ at regions of high negative curvature (such as the poles or the septum). This assumption is motivated by experiments which suggest that MinD localization is dependent on MinJ and that 
642 DivIVA acts as a scaffold which stabilizes MinJ and MinD (see main text). We therefore set the 643 recruitment and detachment rate to $k_{d D}=\alpha \tilde{k}_{d D}$ and $k_{H}=\tilde{k}_{H} / \beta$ at regions of high negative 644 curvature (Fig. S7) where $\alpha$ and $\beta$ denotes dimensionless amplification and reduction prefactors, 645 respectively. The parameters $\tilde{k}_{d D}$ and $\tilde{k}_{H}$ denotes the uniform recruitment and detachment rate 646 which one would obtain if interactions between MinD and MinJ-DivIVA complexes are neglected, i.e. 647 if $\alpha=\beta=1$ (see below).

648

In a cell with no pre-existing division apparatus, the Min system localizes at the poles of the bacteria (see discussion in main text). We model this case by setting $\alpha=4$ and $\beta=3$ at the polar caps and $\alpha=\beta=1$ for the remaining part of the rod-shaped geometry (see Fig. S7 b) The uniform rates were set to $\tilde{k}_{d D}=0.04 \mu \mathrm{m}^{2} / \mathrm{s}$ and $\tilde{k}_{H}=0.1 \mu \mathrm{m}^{2} / \mathrm{s}$ as given in the main text. Simulations show that MinD can be pinned to the cell poles for non-uniform kinetic parameters (Figure $\mathbf{3} \mathbf{c l e f t}$ in main text).

Next, we tested if the polar distribution of MinD decays to a homogeneous protein distribution along the membrane when the rates are uniform over the whole cell body. To this end, we used the steady state polar distribution of MinD (as obtained above) as initial condition for a simulation with uniform rates in the entire geometry, i.e. $\alpha=1, \beta=1$, respectively. We find that for uniform rates MinD proteins preferentially localize near cell center (Figure $\mathbf{3} \mathbf{c}$ left to right in main text). The reason for this unexpected inhomogeneous protein distribution is an interplay between reactions, diffusion and cell geometry. In short, this effect can be explained as follows: MinD detaches from the membrane in an inactive MinD-ADP state and can therefore not rebind to the membrane until it exchanges its nucleotide to switch to an active state MinD-ATP. This results in a source degradation process with the decay length set by $l=\sqrt{D_{D} / \lambda}$. Due to membrane curvature these reaction volumes overlap near the cell poles, which implies an accumulation of inactive MinD-ADP at the cell poles. For a detailed discussion of this geometric effect we refer to [79]. Note that once DivIVA loses its affinity to 
675

676

677

678

679

680

681

682

683

684

685

686

687

688

689

690

691

692

693

694

695

696

697

698

699

700

701

702

703

704

Localization at septum

The curvature sensing protein DivIVA targets the division site and guides MinJ and MinD to the septum (see discussion in the main text). Above we showed that MinD localizes to the cell poles if the recruitment and detachment rate of $\mathrm{MinD}$ are altered at the poles due to interactions with MinJ and DivIVA. For uniform rates, however, the MinD density distribution is spread around mid cell but not sharply localized at the septum as observed in experiments. Sharp localization of MinD at mid cell requires interaction with DivIVA and MinJ and we therefore model this case in the same way as for polar localization: First, we define a narrow region with width $s_{w}=0.14 \mu \mathrm{m}$ at mid cell which represents the septum (Fig. S7 c). We set again $\alpha=4$ and $\beta=3$ at this geometric region to model the interactions of MinD with MinJ and DivIVA implicitly through a modified recruitment and detachment rate. Simulations of the model show that MinD localizes sharply at the septum (Figure 3 d left to right in main text).

\section{Photo-activated localization microscopy (PALM) and cluster analysis}

PALM imaging was performed with the microscope system ELYRA P.1 (Zeiss) and the accompanied Zen software. It is equipped with a $405 \mathrm{~nm}$ Diode-Laser ( $50 \mathrm{~mW}$ ), a $488 \mathrm{~nm}$ laser (200 mW), a $561 \mathrm{~nm}$ laser (200 mW) and a $640 \mathrm{~nm}$ laser (150 mW). Furthermore, an alpha Plan-Apochromat 100x/1,46 Oil DIC M27 objective (Zeiss) was used, in combination with a 1.6x Optovar. The filter sets were the following: a $77 \mathrm{HE} \mathrm{GFP+mRFP+Alexa} 633$ shift free (EX TBP 483+564+642, BS TFT 506+582+659, EM TBP 526+601+688), a 49 DAPI shift free (EX G 365, BS FT 395, EM BP 445/50), a BP 420-480 / LP 750, a BP 495-550 / LP 750, a LP 570 and a LP 655 filter set. Images were recorded with the Andor EM-CCD camera iXon DU 897. Samples expressing $\mathrm{mNeonGreen}$ were illuminated with the $488 \mathrm{~nm}$ laser at 7.4 $\mathrm{mW}$. Samples expressing Dendra2 or PAmCherry were illuminated with the excitation laser $(561 \mathrm{~nm}$, $5.3 \mathrm{~mW}$ ) and activation laser (405 nm). To avoid co-occurrence of multiple events in the same spot, the power of the activation laser was increased stepwise from $0.008 \mathrm{~mW}$ to $1.6 \mathrm{~mW}$. MinJmNeonGreen was illuminated in pseudo-TIRF (total internal reflection fluorescence) mode and recorded at $20 \mathrm{~Hz}$ with 200 camera gain, while Dendra2-MinD and DivIVA-PAmCherry were imaged with the same camera settings in regular wide-field. Analysis was performed in the Zen Black (Zeiss) software. Detection of single emitters was performed with a peak mask size of 9 pixels and a 
705 minimum peak intensity to noise ratio of 6.0., overlapping emitters were discarded. Localization was

706 extrapolated via a 2D Gaussian fitting, and images were drift corrected utilizing a fiducial-based

707 mode with at least 3 beads in focus. Filtering was used to minimize noise, background, out of focus

708 emitters and to exclude beads from the evaluation, according to Tab. 6, different for each respective

709 fluorophore.

710 Cluster analysis was performed in R 3.3.1 [90] utilizing the DBSCAN package $[93,94]$ including OPTICS

711 [95]. Clusters were determined by applying the OPTICS algorithm to the respective molecule tables

712 generated via PALM. The minimal number of points that define a cluster ( $\min P t s$ ) was defined as 10,

713 reflecting apparent clusters seen in rendered PALM imaging, and a minimum distance between

714 cluster edge points (epsCl) of 20 and $30 \mathrm{~nm}$ for MinD and DivlVA, respectively, according to the

715 observed density of protein localization. 


\section{References}

718 1. Bi, E.F., and Lutkenhaus, J. (1991). FtsZ ring structure

2. Margolin, W. (2005). FtsZ and the division of prokaryotic cells and organelles. Nat Rev Mol Cell Biol 6, 862-871.

3. Rowlett, V.W., and Margolin, W. (2015). The Min system and other nucleoid-independent regulators of $Z$ ring positioning. Front Microbiol 6, 478.

4. Shih, Y.L., and Rothfield, L. (2006). The bacterial cytoskeleton. Microbiology and molecular biology reviews : MMBR 70, 729-754.

5. Lutkenhaus, J., Pichoff, S., and Du, S. (2012). Bacterial cytokinesis: From $Z$ ring to divisome. Cytoskeleton (Hoboken) 69, 778-790.

6. Ortiz, C., Natale, P., Cueto, L., and Vicente, M. (2016). The keepers of the ring: regulators of FtsZ assembly. FEMS Microbiol Rev 40, 57-67.

7. Errington, J., and Wu, L.J. (2017). Cell Cycle Machinery in Bacillus subtilis. Subcell Biochem 84, 67-101.

8. Haeusser, D.P., and Margolin, W. (2016). Splitsville: structural and functional insights into the dynamic bacterial Z ring. Nat Rev Microbiol 14, 305-319.

9. Bisson-Filho, A.W., Hsu, Y.P., Squyres, G.R., Kuru, E., Wu, F., Jukes, C., Sun, Y., Dekker, C., Holden, S., VanNieuwenhze, M.S., et al. (2017). Treadmilling by FtsZ filaments drives peptidoglycan synthesis and bacterial cell division. Science 355, 739-743.

10. Wu, L.J., and Errington, J. (2004). Coordination of cell division and chromosome segregation by a nucleoid occlusion protein in Bacillus subtilis. Cell 117, 915-925. 
11. Bernhardt, T.G., and de Boer, P.A. (2005). SlmA, a nucleoidassociated, FtsZ binding protein required for blocking septal ring assembly over Chromosomes in E. coli. Mol Cell 18, 555-564.

12. Tonthat, N.K., Arold, S.T., Pickering, B.F., Van Dyke, M.W., Liang, S., Lu, Y., Beuria, T.K., Margolin, W., and Schumacher, M.A. (2011). Molecular mechanism by which the nucleoid occlusion factor, SImA, keeps cytokinesis in check. The EMBO journal 30, 154-164.

13. Tonthat, N.K., Milam, S.L., Chinnam, N., Whitfill, T., Margolin, W., and Schumacher, M.A. (2013). SlmA forms a higher-order structure on DNA that inhibits cytokinetic Zring formation over the nucleoid. Proc Natl Acad Sci U S A 110, 10586-10591.

14. Adams, D.W., Wu, L.J., and Errington, J. (2015). Nucleoid occlusion protein Noc recruits DNA to the bacterial cell membrane. The EMBO journal 34, 491-501.

15. de Boer, P.A., Crossley, R.E., and Rothfield, L.I. (1988). Isolation and properties of $\min B$, a complex genetic locus involved in correct placement of the division site in Escherichia coli. J Bacteriol 170, 2106-2112.

16. de Boer, P.A., Crossley, R.E., and Rothfield, L.I. (1992). Roles of MinC and MinD in the site-specific septation block mediated by the MinCDE system of Escherichia coli. J Bacteriol 174, 63-70.

17. Hu, Z., and Lutkenhaus, J. (1999). Topological regulation of cell division in Escherichia coli involves rapid pole to pole oscillation of the division inhibitor MinC under the control of MinD and MinE. Molecular microbiology 34, 82-90.

18. Hu, Z., Gogol, E.P., and Lutkenhaus, J. (2002). Dynamic assembly of MinD on phospholipid vesicles regulated by ATP and MinE. Proc Natl Acad Sci U S A 99, 6761-6766. 
19. Szeto, T.H., Rowland, S.L., Rothfield, L.I., and King, G.F. (2002). Membrane localization of MinD is mediated by a Cterminal motif that is conserved across eubacteria, archaea, and chloroplasts. Proc Natl Acad Sci U S A 99, 1569315698.

20. Lackner, L.L., Raskin, D.M., and de Boer, P.A. (2003). ATPdependent interactions between Escherichia coli Min proteins and the phospholipid membrane in vitro. J Bacteriol 185, 735-749.

21. Mileykovskaya, E., Fishov, I., Fu, X., Corbin, B.D., Margolin, W., and Dowhan, W. (2003). Effects of phospholipid composition on MinD-membrane interactions in vitro and in vivo. J Biol Chem 278, 22193-22198.

22. Hu, Z., Mukherjee, A., Pichoff, S., and Lutkenhaus, J. (1999). The MinC component of the division site selection system in Escherichia coli interacts with FtsZ to prevent polymerization. Proc Natl Acad Sci U S A 96, 14819-14824.

23. Hu, Z., and Lutkenhaus, J. (2001). Topological regulation of cell division in E. coli. spatiotemporal oscillation of MinD requires stimulation of its ATPase by MinE and phospholipid. Mol Cell 7, 1337-1343.

24. Touhami, A., Jericho, M., and Rutenberg, A.D. (2006). Temperature dependence of MinD oscillation in Escherichia coli: running hot and fast. J Bacteriol 188, 76617667.

25. Park, K.T., Wu, W., Battaile, K.P., Lovell, S., Holyoak, T., and Lutkenhaus, J. (2011). The Min oscillator uses MinDdependent conformational changes in MinE to spatially regulate cytokinesis. Cell 146, 396-407.

26. Schweizer, J., Loose, M., Bonny, M., Kruse, K., Monch, I., and Schwille, P. (2012). Geometry sensing by self-organized protein patterns. Proc Natl Acad Sci U S A 109, 1528315288. 
27. Loose, M., Fischer-Friedrich, E., Ries, J., Kruse, K., and Schwille, P. (2008). Spatial regulators for bacterial cell division self-organize into surface waves in vitro. Science 320, 789-792.

28. Wu, F., van Schie, B.G., Keymer, J.E., and Dekker, C. (2015). Symmetry and scale orient Min protein patterns in shaped bacterial sculptures. Nat Nanotechnol 10, 719-726.

29. Wu, F., Halatek, J., Reiter, M., Kingma, E., Frey, E., and Dekker, C. (2016). Multistability and dynamic transitions of intracellular Min protein patterns. Mol Syst Biol 12, 873.

30. Huang, K.C., Meir, Y., and Wingreen, N.S. (2003). Dynamic structures in Escherichia coli: spontaneous formation of MinE rings and MinD polar zones. Proc Natl Acad Sci U S A 100, 12724-12728.

31. Fange, D., and Elf, J. (2006). Noise-induced Min phenotypes in E. coli. PLoS Comput Biol 2, e80.

32. Halatek, J., and Frey, E. (2012). Highly canalized MinD transfer and MinE sequestration explain the origin of robust MinCDE-protein dynamics. Cell Rep 1, 741-752.

33. Halatek, J., and Frey, E. (2018). Rethinking pattern formation in reaction-diffusion systems. Nature Physics 14 , 507-514.

34. Denk, J., Kretschmer, S., Halatek, J., Hartl, C., Schwille, P., and Frey, E. (2018). MinE conformational switching confers robustness on self-organized Min protein patterns. Proc Natl Acad Sci U S A 115, 4553-4558.

35. Hoffmann, M., and Schwarz, U.S. (2014). Oscillations of Min-proteins in micropatterned environments: a threedimensional particle-based stochastic simulation approach. Soft Matter 10, 2388-2396.

36. Shen, B., and Lutkenhaus, J. (2010). Examination of the interaction between FtsZ and MinCN in E. coli suggests 
how MinC disrupts Z rings. Molecular microbiology 75, 1285-1298.

37. Shen, B., and Lutkenhaus, J. (2009). The conserved Cterminal tail of FtsZ is required for the septal localization and division inhibitory activity of $\mathrm{MinC}(\mathrm{C}) / \mathrm{MinD}$. Molecular microbiology 72, 410-424.

38. Dajkovic, A., Lan, G., Sun, S.X., Wirtz, D., and Lutkenhaus, J. (2008). MinC spatially controls bacterial cytokinesis by antagonizing the scaffolding function of FtsZ. Current biology : CB 18, 235-244.

39. Blasios, V., Bisson-Filho, A.W., Castellen, P., Nogueira, M.L., Bettini, J., Portugal, R.V., Zeri, A.C., and Gueiros-Filho, F.J. (2013). Genetic and biochemical characterization of the MinC-FtsZ interaction in Bacillus subtilis. PLoS One 8, e60690.

40. Ebersbach, G., and Gerdes, K. (2005). Plasmid segregation mechanisms. Annu Rev Genet 39, 453-479.

41. Gitai, Z. (2006). Plasmid segregation: a new class of cytoskeletal proteins emerges. Current biology : CB 16, R133-136.

42. Hu, Z., and Lutkenhaus, J. (2003). A conserved sequence at the $\mathrm{C}$-terminus of MinD is required for binding to the membrane and targeting MinC to the septum. Molecular microbiology 47, 345-355.

43. de Boer, P.A., Crossley, R.E., Hand, A.R., and Rothfield, L.I. (1991). The MinD protein is a membrane ATPase required for the correct placement of the Escherichia coli division site. The EMBO journal 10, 4371-4380.

44. Conti, J., Viola, M.G., and Camberg, J.L. (2015). The bacterial cell division regulators MinD and MinC form polymers in the presence of nucleotide. FEBS Lett 589, 201-206. 
45. Ghosal, D., Trambaiolo, D., Amos, L.A., and Löwe, J. (2014). MinCD cell division proteins form alternating copolymeric cytomotive filaments. Nat Commun 5, 5341.

46. Reeve, J.N., Mendelson, N.H., Coyne, S.I., Hallock, L.L., and Cole, R.M. (1973). Minicells of Bacillus subtilis. J Bacteriol 114, 860-873.

47. de Boer, P.A., Crossley, R.E., and Rothfield, L.I. (1990). Central role for the Escherichia coli minC gene product in two different cell division-inhibition systems. Proc Natl Acad Sci U S A 87, 1129-1133.

48. Raskin, D.M., and de Boer, P.A. (1997). The MinE ring: an FtsZ-independent cell structure required for selection of the correct division site in E. coli. Cell 91, 685-694.

49. Hale, C.A., Meinhardt, H., and de Boer, P.A. (2001). Dynamic localization cycle of the cell division regulator MinE in Escherichia coli. The EMBO journal 20, 1563-1572.

50. Ma, L.Y., King, G., and Rothfield, L. (2003). Mapping the MinE site involved in interaction with the MinD division site selection protein of Escherichia coli. J Bacteriol 185, 49484955.

51. Hsieh, C.W., Lin, T.Y., Lai, H.M., Lin, C.C., Hsieh, T.S., and Shih, Y.L. (2010). Direct MinE-membrane interaction contributes to the proper localization of MinDE in E. coli. Molecular microbiology 75, 499-512.

52. Loose, M., Fischer-Friedrich, E., Herold, C., Kruse, K., and Schwille, P. (2011). Min protein patterns emerge from rapid rebinding and membrane interaction of MinE. Nat Struct Mol Biol 18, 577-583.

53. Vecchiarelli, A.G., Li, M., Mizuuchi, M., Hwang, L.C., Seol, Y., Neuman, K.C., and Mizuuchi, K. (2016). Membrane-bound MinDE complex acts as a toggle switch that drives Min oscillation coupled to cytoplasmic depletion of MinD. Proc Natl Acad Sci U S A 113, E1479-1488. 
54. Halatek, J., Brauns, F., and Frey, E. (2018). Self-organization principles of intracellular pattern formation. Philos Trans $R$ Soc Lond B Biol Sci 373.

55. Cha, J.H., and Stewart, G.C. (1997). The divIVA minicell locus of Bacillus subtilis. J Bacteriol 179, 1671-1683.

56. Edwards, D.H., and Errington, J. (1997). The Bacillus subtilis DivIVA protein targets to the division septum and controls the site specificity of cell division. Molecular microbiology 24, 905-915.

57. Lenarcic, R., Halbedel, S., Visser, L., Shaw, M., Wu, L.J., Errington, J., Marenduzzo, D., and Hamoen, L.W. (2009). Localisation of DivIVA by targeting to negatively curved membranes. The EMBO journal 28, 2272-2282.

58. Bramkamp, M., Emmins, R., Weston, L., Donovan, C., Daniel, R.A., and Errington, J. (2008). A novel component of the division-site selection system of Bacillus subtilis and a new mode of action for the division inhibitor MinCD. Molecular microbiology 70, 1556-1569.

59. Patrick, J.E., and Kearns, D.B. (2008). MinJ (YvjD) is a topological determinant of cell division in Bacillus subtilis. Molecular microbiology 70, 1166-1179.

60. Jemth, P., and Gianni, S. (2007). PDZ domains: folding and binding. Biochemistry 46, 8701-8708.

61. van Baarle, S., and Bramkamp, M. (2010). The MinCDJ system in Bacillus subtilis prevents minicell formation by promoting divisome disassembly. PLoS One 5, e9850.

62. Bach, J.N., Albrecht, N., and Bramkamp, M. (2014). Imaging DivIVA dynamics using photo-convertible and activatable fluorophores in Bacillus subtilis. Front Microbiol 5, 59.

63. Marston, A.L., Thomaides, H.B., Edwards, D.H., Sharpe, M.E., and Errington, J. (1998). Polar localization of the MinD protein of Bacillus subtilis and its role in selection of the mid-cell division site. Genes Dev 12, 3419-3430. 
942 64. Marston, A.L., and Errington, J. (1999). Selection of the midcell division site in Bacillus subtilis through MinDdependent polar localization and activation of MinC. Molecular microbiology 33, 84-96.

65. Gregory, J.A., Becker, E.C., and Pogliano, K. (2008). Bacillus subtilis MinC destabilizes FtsZ-rings at new cell poles and contributes to the timing of cell division. Genes Dev 22, 3475-3488.

66. Gurskaya, N.G., Verkhusha, V.V., Shcheglov, A.S.,

67. Pedelacq, J.D., Cabantous, S., Tran, T., Terwilliger, T.C., and

70. Subach, F.V., Patterson, G.H., Manley, S., Gillette, J.M., Lippincott-Schwartz, J., and Verkhusha, V.V. (2009). Photoactivatable mCherry for high-resolution two-color fluorescence microscopy. Nat Methods 6, 153-159. 
973 71. Ando, R., Mizuno, H., and Miyawaki, A. (2004). Regulated fast nucleocytoplasmic shuttling observed by reversible protein highlighting. Science 306, 1370-1373.

72. Chang, H., Zhang, M., Ji, W., Chen, J., Zhang, Y., Liu, B., Lu, J., Zhang, J., Xu, P., and $X u, T$. (2012). A unique series of reversibly switchable fluorescent proteins with beneficial properties for various applications. Proc Natl Acad Sci U S A 109, 4455-4460.

73. Stockmar, I., Feddersen, H., Cramer, K., Gruber, S., Jung, K., Bramkamp, M., and Shin, J.Y. (2018). Optimization of sample preparation and green color imaging using the $\mathrm{mNeonGreen} \mathrm{fluorescent} \mathrm{protein} \mathrm{in} \mathrm{bacterial} \mathrm{cells} \mathrm{for}$ photoactivated localization microscopy. Sci Rep 8, 10137.

75. Eswaramoorthy, P., Erb, M.L., Gregory, J.A., Silverman, J., Pogliano, K., Pogliano, J., and Ramamurthi, K.S. (2011). Cellular architecture mediates DivIVA ultrastructure and regulates min activity in Bacillus subtilis. MBio 2.

76. Maass, S., Sievers, S., Zuhlke, D., Kuzinski, J., Sappa, P.K., Muntel, J., Hessling, B., Bernhardt, J., Sietmann, R., Volker, U., et al. (2011). Efficient, global-scale quantification of absolute protein amounts by integration of targeted mass spectrometry and two-dimensional gel-based proteomics. Anal Chem 83, 2677-2684.

77. Karoui, M.E., and Errington, J. (2001). Isolation and characterization of topological specificity mutants of $\mathrm{minD}$ in Bacillus subtilis. Molecular microbiology 42, 1211-1221.

78. Howard, M. (2004). A mechanism for polar protein localization in bacteria. J Mol Biol 335, 655-663. 
79. Thalmeier, D., Halatek, J., and Frey, E. (2016). Geometryinduced protein pattern formation. Proc Natl Acad Sci U S A 113, 548-553.

80. Ramamurthi, K.S., Lecuyer, S., Stone, H.A., and Losick, R. (2009). Geometric cue for protein localization in a bacterium. Science 323, 1354-1357.

81. Eswara, P.J., and Ramamurthi, K.S. (2017). Bacterial Cell Division: Nonmodels Poised to Take the Spotlight. Annu Rev Microbiol 71, 393-411.

82. Kretschmer, S., and Schwille, P. (2016). Pattern formation on membranes and its role in bacterial cell division. Curr Opin Cell Biol 38, 52-59.

83. Vecchiarelli, A.G., Li, M., Mizuuchi, M., and Mizuuchi, K. (2014). Differential affinities of MinD and MinE to anionic phospholipid influence Min patterning dynamics in vitro. Molecular microbiology 93, 453-463.

84. Kumar, M., Mommer, M.S., and Sourjik, V. (2010). Mobility of cytoplasmic, membrane, and DNA-binding proteins in Escherichia coli. Biophys J 98, 552-559.

85. Rodrigues, C.D., and Harry, E.J. (2012). The Min system and nucleoid occlusion are not required for identifying the division site in Bacillus subtilis but ensure its efficient utilization. PLoS Genet 8, e1002561.

86. Sieber, J.J., Willig, K.I., Kutzner, C., Gerding-Reimers, C., Harke, B., Donnert, G., Rammner, B., Eggeling, C., Hell, S.W., Grubmuller, H., et al. (2007). Anatomy and dynamics of a supramolecular membrane protein cluster. Science 317, 1072-1076.

87. Anagnostopoulos, C., and Spizizen, J. (1961). Requirements for Transformation in Bacillus Subtilis. J Bacteriol 81, 741746. 
1036 88. Gavet, O., and Pines, J. (2010). Activation of cyclin B1-Cdk1

1037 synchronizes events in the nucleus and the cytoplasm at

1038 mitosis. J Cell Biol 189, 247-259.

1039

89. Axelrod, D., Koppel, D.E., Schlessinger, J., Elson, E., and

1040

1041

1042

1043

1044

1045

1046

1047

1048

1049

1050

1051

1052

1053

1054

1055

1056

1057

1058

1059

1060 Webb, W.W. (1976). Mobility measurement by analysis of fluorescence photobleaching recovery kinetics. Biophys J 16, 1055-1069.

90. Team, R.C. (2016). R: A Language and Environment for Statistical Computing. R Foundation for Statistical Computing.

91. Wickham, H. (2009). ggplot2: Elegant Graphics for Data Analysis. Springer-Verlag New York.

92. Baty, F., Ritz, C., Charles, S., Brutsche, M., Flandrois, J.-P., and Delignette-Muller, M.-L. (2015). A Toolbox for Nonlinear Regression in R: The Package nlstools. Journal of Statistical Software 66, 1-21.

93. Ester, M.K., H.P.; Sander, J.; Xu, X. (1996). A Density-Based Algorithm for Discovering Clusters in Large Spatial Databases with Noise. KDD 96, 226-231.

94. Hahsler, M., and Piekenbrock, M. (2017). dbscan: Density Based Clustering of Applications with Noise (DBSCAN) and Related Algorithms.

95. Ankerst, M., Breunig, M.M., Kriegel, H.P., and Sander, J. (1999). OPTICS: Ordering points to identify the clustering structure. Sigmod Record, Vol 28, No 2 - June 1999, 49-60. 
bioRxiv preprint doi: https://doi.org/10.1101/2020.04.29.068676; this version posted April 30, 2020. The copyright holder for this preprint (which

was not certified by peer review) is the author/funder, who has granted bioRxiv a license to display the preprint in perpetuity. It is made available under aCC-BY-NC-ND 4.0 International license.

1062 Figures

a

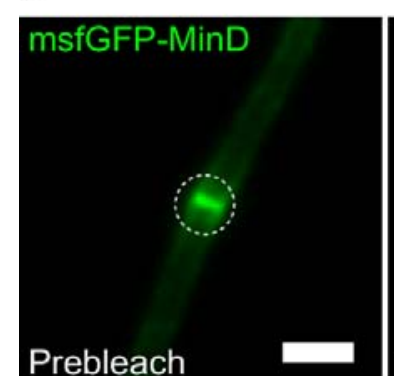

1063
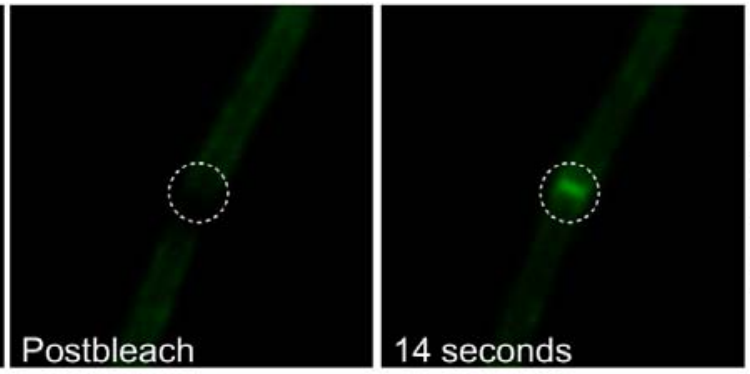

b
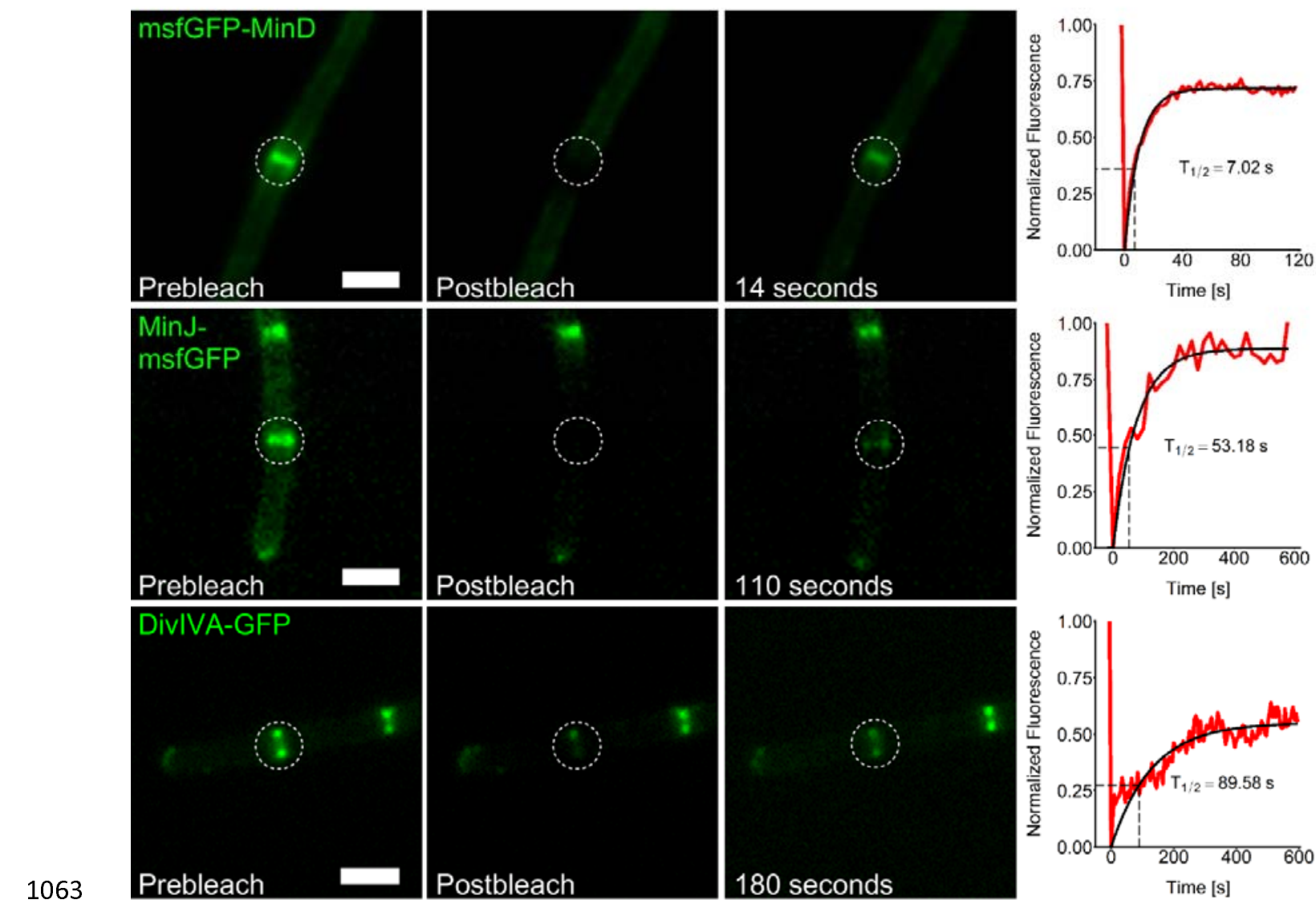

1064

Figure 1: FRAP experiments in growing B. subtilis cells reveal Min protein dynamics. (a)

Representative microscopy images of msfGFP-MinD (BHF017), MinJ-msfGFP (BHF007) and DivIVA-

GFP (1803) before bleaching the indicated spot with a $488 \mathrm{~nm}$ laser pulse, directly after bleaching

and after recovery of fluorescence. Scale bars $2 \mu \mathrm{m}$. (b) Representation of the normalized

fluorescence recovery in the green channel over time. $T_{1 / 2}=$ time when fluorescence recovery

reaches half height of total recovery, indicated on the graph with a dashed square. The red line methods (Eq. 1-3). 


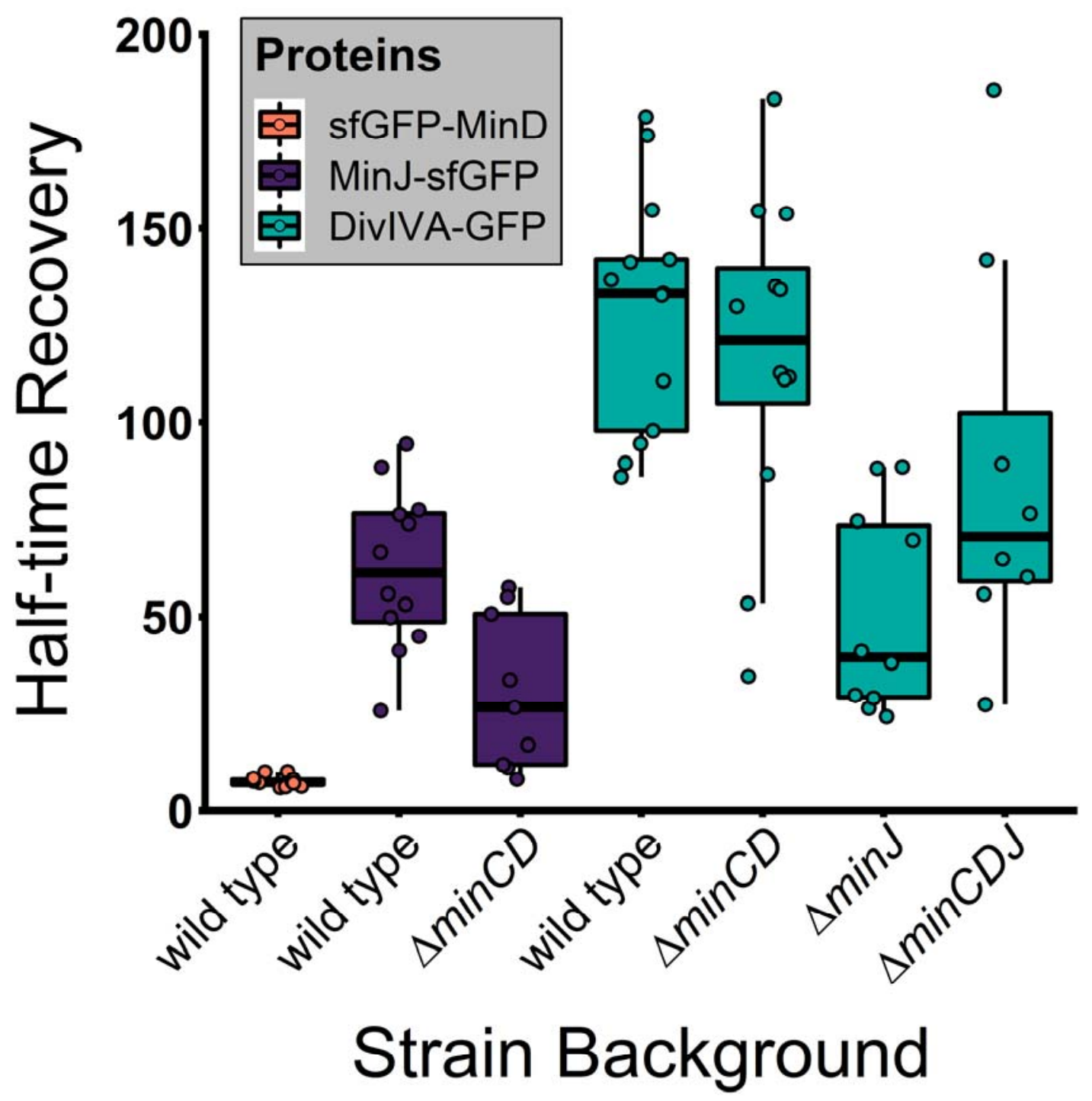

Figure 2: $B$. subtilis Min proteins form dynamic complexes. Shown are half-time recovery median indicated by black bar inside each box. Each box represents a different strain, also see Tab. 2 for mean values. Every dot represents a single FRAP experiment, $n \geq 8$. 
a

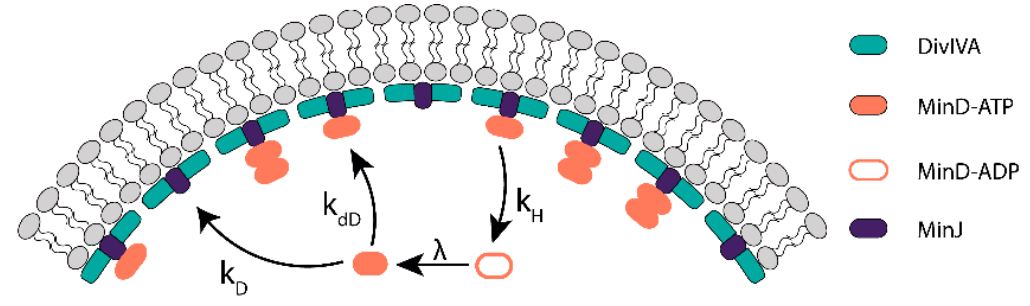

b

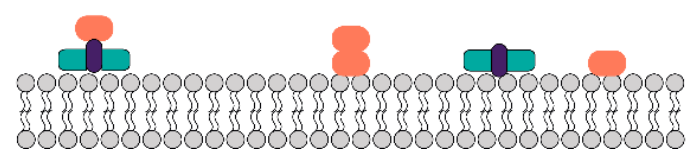

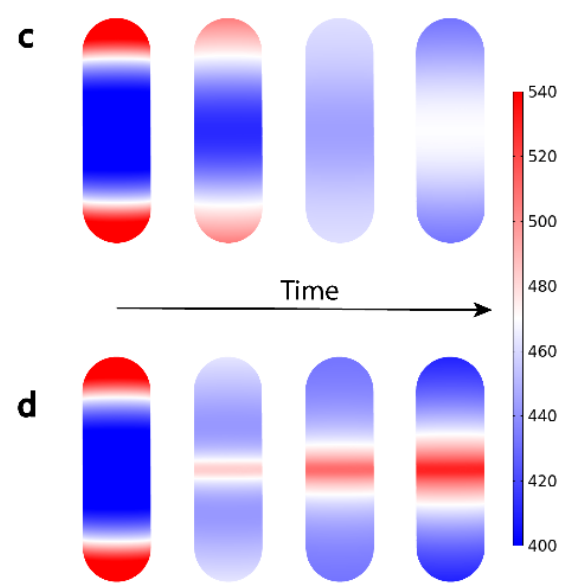

1082

1083

1084

1085

1086

1087

1088

1089

1090

1091

1092

1093

1094

1095

1096

1097

1098

Figure 3: Model and simulation of the Min system in B. subtilis. (a) The geometry sensing protein DivIVA (green) preferentially localizes to regions of highest negative curvature and stabilizes MinJ (purple) to these regions. Membrane-bound DivIVA acts as a template for MinD-recruitment of cytosolic MinD-ATP (orange) facilitated through MinJ. MinD-ATP binds to the membrane with a rate $\mathrm{k}_{\mathrm{D}}$ and recruits cytosolic MinD-ATP with a (space-dependent) recruitment rate $\mathrm{k}_{\mathrm{dD}}$ to the membrane. Membrane-bound MinD is stabilized by MinJ-DivIVA complexes, which is reflected in a space-dependent detachment rate $\mathrm{k}_{\mathrm{det}}$. After detachment, MinD is in a hydrolysed state MinD-ADP and can rebind to the membrane only after nucleotide exchange with a rate $\lambda$. (b) MinD binds to flat membrane regions as well and recruits MinD-ATP from the cytosol. Binding to flat regions is, however, less favored due to the lower concentration of MinJ-DivlVA complexes. (c) Simulation of the reaction-diffusion model in a $3 \mathrm{D}$ rod-shaped cell; shown is the membrane-bound MinD density distribution. As initial condition we take the steady state distribution of the scenario where DivIVA is localized at the poles (left figure). At simulation start we assume that MinD is losing its affinity to the poles by making the recruitment and detachment rate uniform on the entire cell membrane (this is for example the case at the onset of septum formation). From left to right the time evolution of membrane-bound MinD is shown, where the very right side shows the final steady state density distribution. We find that polar localization of MinD becomes unstable and that the proteins 
bioRxiv preprint doi: https://doi.org/10.1101/2020.04.29.068676; this version posted April 30, 2020. The copyright holder for this preprint (which

was not certified by peer review) is the author/funder, who has granted bioRxiv a license to display the preprint in perpetuity. It is made available under aCC-BY-NC-ND 4.0 International license.

1099 preferentially localize at the cell center. (d) To test whether MinD can be localized at midplane

1100 through MinJ-DivlVA complexes after septum formation, we took the same initial condition as in (c)

1101 and enhanced recruitment and decreased detachment near midcell, respectively. We find that MinD

1102 can sharply localize at the septum. 

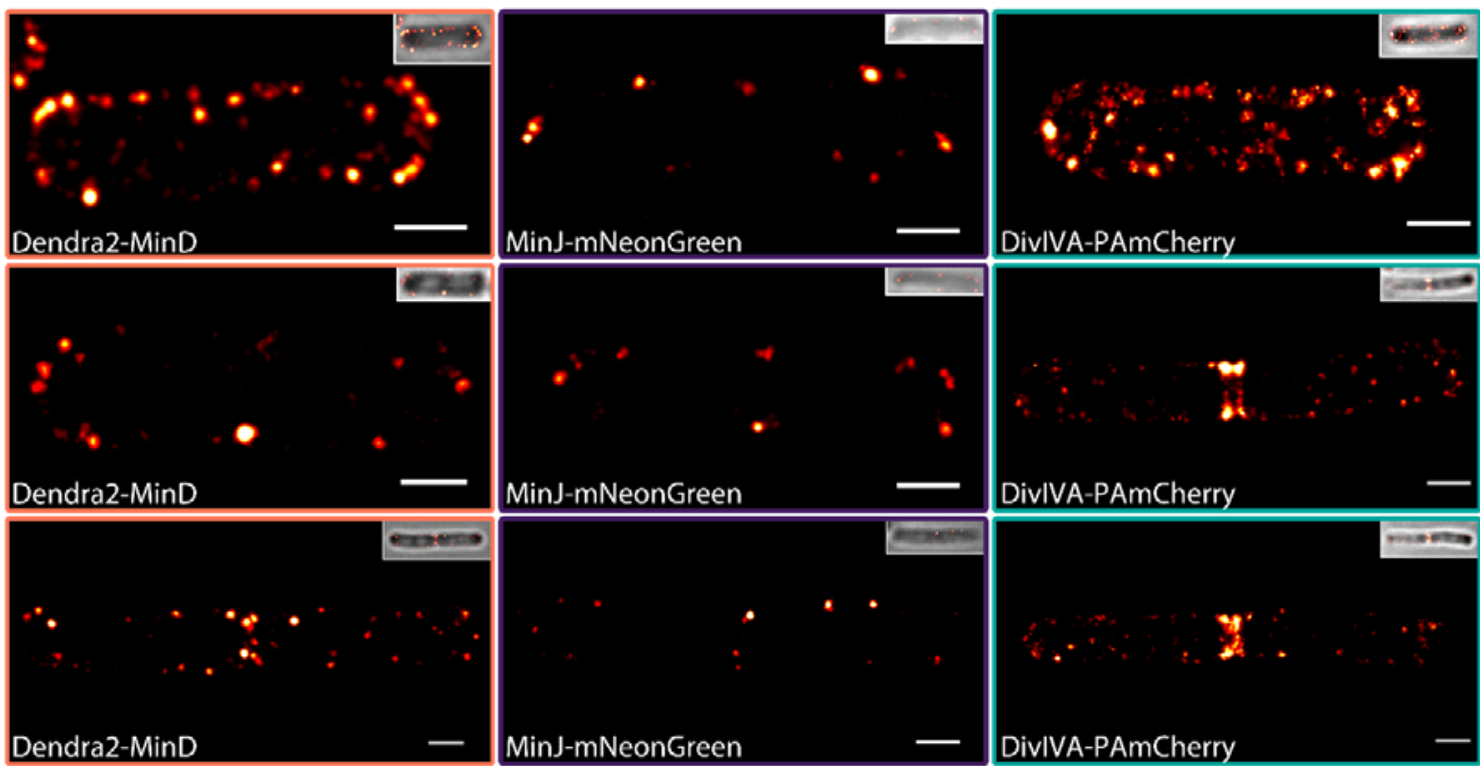

1106

1107

Figure 4: PALM imaging of strains expressing Dendra2-MinD, MinJ-mNeonGreen and DivIVA-

PAmCherry. Representative PALM images of Dendra2-MinD (BHF011), MinJ-mNeonGreen (JB40) and

DivIVA-PAmCherry (JB37) expressing cells at different divisional states. Upon formation of a division 

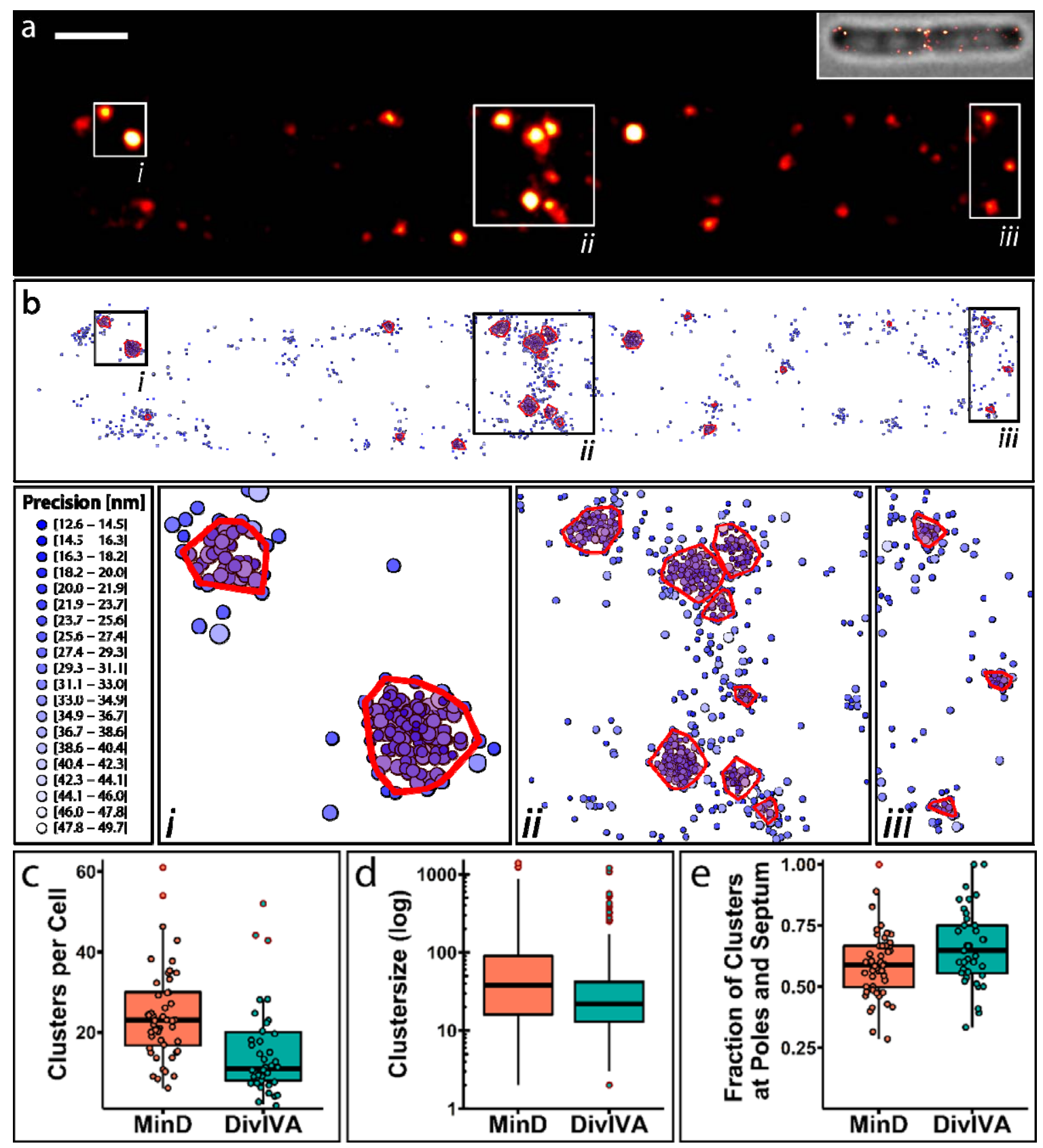

1118 Figure 5: PALM imaging and representative cluster analysis of Dendra2-MinD and DivIVA-

PAmCherry. (a) Representative PALM image of Dendra2-MinD (BHF011) in a cell in late division state.

1120 Scale bar $500 \mathrm{~nm}$. (b) Cluster analysis of the same PALM data with three highlighted regions (i, ii and

1121 iii). Cluster analysis was performed in R using the OPTICS algorithm from the DBSCAN package. Every

1122 point indicates a single event and thus a Dendra2-MinD/DivIVA-PAmCherry protein, precision is 
bioRxiv preprint doi: https://doi.org/10.1101/2020.04.29.068676; this version posted April 30, 2020. The copyright holder for this preprint (which

was not certified by peer review) is the author/funder, who has granted bioRxiv a license to display the preprint in perpetuity. It is made available under aCC-BY-NC-ND 4.0 International license.

1124 DivIVA-PAmCherry per cell (MinD, $n_{\text {cells }}=48$, DivIVA, $n_{\text {cells }}=37$ ). (d) Boxplot of the number of proteins

1125 per cluster, no jitter is shown due to high sample number (Dendra2-MinD, $n_{\text {clusters }}=1171$, DivIVA-

1126 PAmCherry, $\mathrm{n}_{\text {clusters }}=586$ ). (e) Boxplot of fraction of clusters localized at poles and septa per cell

1127 (MinD, $n_{\text {cells }}=48$, DivIVA, $n_{\text {cells }}=37$ ). Outliers in boxplots are indicated by red outline. 